\title{
Framed field experiment on resource scarcity \& extraction: Path-dependent generosity within sequential water appropriation i $^{2}$
}

\author{
Alexander Pfaff ${ }^{\mathrm{a}, 1}$, Maria Alejandra Vélez ${ }^{\mathrm{b}, *, 1}$, Pablo Andres Ramos ${ }^{\mathrm{c}}$, Adriana Molina ${ }^{\mathrm{d}}$ \\ a Sanford School of Public Policy, Duke University, 186 Rubenstein Hall, Box 90312, Durham, NC 27708, USA \\ ${ }^{\mathrm{b}}$ Facultad de Administración, Universidad de Los Andes, Calle 21 \# 1-20 Ed. SD, Bogotá, Colombia \\ c School of Rural and Environmental Studies, Pontificia Universidad Javeriana, Transv 4 \# 42 - 00. 8th floor, Bogotá, Colombia \\ ${ }^{\mathrm{d}}$ Consultant Office of Evaluation and Oversight, Inter-American Development Bank, USA
}

\section{A R T I C L E I N F O}

\section{Article history:}

Received 27 August 2014

Received in revised form 29 April 2015

Accepted 2 June 2015

Available online 19 June 2015

\begin{abstract}
A B S T R A C T
How one treats others is important within collective action. We ask if resource scarcity in the past, due to its ef fects upon past behaviors, influences current other-regarding behaviors. Contrasting theories and empirical findings on scarcity motivate our framed field experiment. Participants are rural Colombian farmers who have experienced scarcity of water within irrigation. We randomly assign participants to groups and places on group canals. Places order extraction decisions. Our treatments are sequences of scarcities: 'from lower to higher resources' involves four rounds each of 20,60, then 100 units of water; 'from higher to lower resources' reverses the ordering. We find that upstream farmers extract more, but a lower share, when facing higher resources. Further they take a larger share of higher resources when they faced lower resources in earlier rounds (relative to when facing higher resources initially). That is inconsistent with leading models of responses to scarcity which focus upon one's own gain. It is consistent with lowering one's weight on others to, for instance, rationalize having left them little. Our results suggest that facing higher scarcity can erode the bases for collective actions. For establishing new institutions, timing relative to scarcity could affect the probability of success.
\end{abstract}

(c) 2015 Elsevier B.V. All rights reserved.

\section{Introduction}

Institution building sometimes fails. Research about local institutions for common property resources - advanced and symbolized by Ostrom (1990) - includes potential failure alongside its core assertion that local institutions can arise to solve dilemmas. Ostrom's characterization of building local institutions as providing public goods succinctly captures a potential for failure, as incentives hover even after success. Hovering challenges are the core of literatures addressing, for instance, institutional erosion and decay. Institutions in principle evolve due to learning, changes in context, or pure trial and error (Ostrom, 2009a, 2009b); however, they could devolve. For instance, any institution may fail by not taking into account significant shifts in relevant environmental factors (Greif, 2014) or critical social and political factors (Agrawal, 2001), even when that very same institution previously has succeeded in guiding many relevant local behaviors.

\footnotetext{
is The findings and interpretations of the authors do not necessarily represent the views of the Inter-American Development Bank.

* Corresponding author.

E-mail addresses: alex.pfaff@duke.edu (A. Pfaff), mavelez@uniandes.edu.co (M.A. Vélez), p.ramos@javeriana.edu.co (P.A. Ramos), almolina@iadb.org (A. Molina).

1 Co-lead authors.
}

Many factors can enhance or erode the chances that the individuals involved will make sufficient contributions to build and maintain local institutions (Ostrom, 1990 among many others), noting that for common-pool resources contributions occur both in provision and in appropriation (Ostrom et al., 1994b). For instance, the discussion in Feeny et al. $(1990,1996)$ of settings where tragedies of the commons may be avoided also indicates which situations are more likely to be tragic. This all implies a margin, i.e., that some combinations of factors yield significant uncertainty about whether collective actions will succeed. Within these collective challenges, how people treat others - driven by, for instance, the weight given to others' welfare - can tip the balance in terms of whether there exists sufficient collective willingness to successfully coordinate the provision and the maintenance of a common-pool resource (Ostrom, 1998).

Our focus is the impacts of facing resource scarcity on willingness to restrict one's appropriation. Specifically, we consider durable impact on other-regarding behavior of having faced scarcity in the past. We are interested in such durable implications for sequential settings, a very common type of setting for asymmetric appropriation of commonpool resources: e.g., on canals, the upstream appropriators affect what is available to downstream - but not vice versa. In such settings, scarcities in the past may have led upstream appropriators to take higher shares from pools with lower resources. 
Such past behaviors, in turn, can erode (or, if generous, enhance) the interpersonal bases for current or future collective action. Selfish responses to scarcity in the past can generate selfish behaviors today, undermining coordination.

A focus on scarcity per se is not unique, though few employ experiments as we have done here. ${ }^{2}$ Some report that absolute extraction falls with scarcity, although such self-limitation is not sufficient to head off depletion (Osés-Eraso, Udina and Viladrich-Grau, 2008; Osés-Eraso and Viladrich-Grau, 2007). Others report that higher scarcity increases extraction on average (Blanco et al., 2015; D'Exelle et al., 2009), though for the D'Exelle et al. (2009) result the mode did not change and, even when facing higher scarcity, equal sharing remains the most common decision. Outside of experiments, scarcity of renewable resources, and in particular water, is identified as a driver of "environmental conflict" (see, e.g., Homer-Dixon (1991, 1994, 1999); Libiszewski, (1992)) alongside and interacting with power relations and various factors in production and politics (Glaser et al., 2013). Such literature has specifically indicated the need to gather additional empirical evidence to understand the role of scarcity as a driver (Meierding, 2013), including for conflict at smaller scales (Theisen et al., 2013). Adding to these very brief summaries, Section 2 below describes a number of other related literatures.

A focus upon durable effects of scarcity places our study experimentally randomizing scarcity - in the literature on path dependence. That includes experiments with multiple equilibria, e.g., exploring durable implications of heterogeneity in otherregarding preferences and beliefs. For instance, Camerer and Fehr (2006) discuss payoffs based upon others' actions, so shifts in the beliefs about the distribution of types shift equilibria. Other-regarding behaviors early in interactions clearly can shift one's beliefs and many experiments have documented lasting impacts of early behaviors (e.g., Pfaff et al., 2015a, 2015b).

We believe that our examination of the timing of resource scarcity is unique and policy relevant. Considering that durable effects of scarcity is rare (yet see Blanco et al. (2015)) we also provide sharply contrasting theoretical perspectives upon how past resource scarcity should matter. Theoretically, Ostrom (2009a) emphasizes how one's own marginal extraction benefit varies with current scarcity, but does not model past scarcity. Tversky and Kahneman (1986) suggest that past scarcity could affect one's own "reference point" - likely based upon past extraction - which can affect one's marginal benefits from any given level of current extraction. Such a model suggests that higher past scarcity will lower one's own current marginal benefits and, thus, raise the willingness to self-restrict. Yet a model in which due to higher past scarcity one lowers the weight on others, e.g., to rationalize having given others little in tougher times, suggests the opposite: facing higher past scarcities could motivate less self-restriction.

Contrasting predictions suggest empirical testing of path dependence, i.e., past scarcity's effects. We employ the control offered by 'framed field experiments' (Harrison and List, 2004) in order to lessen any confounding of shifts in scarcity level with other factors that affect the appropriation of resources. ${ }^{3}$ Observational data can help to evaluate scarcity's impacts (see Carter and Castillo (2005)'s use of shocks). However, randomized orderings of scarcities improve tests of whether

\footnotetext{
2 Our purely experimental approach to scarcity differs fundamentally from the important questions that are taken up within, for example, Shah et al. (2012); Mullainathan and Shafir (2013) and Mani et al. (2013). They explore actual ongoing resource scarcity and actual poverty - distinct from small shifts within games - which could generate a permanent mental model that involves cognitive limitations due to varied past physical restrictions.

${ }^{3}$ By 'framed field experiments' we mean decision-making, lab-style experiments that are conducted with a relevant population. That class differs from randomized field experiments or interventions (e.g. Sekhon and Titiunik, 2012; Green and Gerber, 2003; Green and Thorley, 2014). For these types of natural experiments on collective action see, e.g., a review de Rooij et al. (2009).
}

current other-regarding behavior is affected by past resource scarcity. We design away abundance, so that self-restriction does aid others.

Using laboratory and field experiments to study water is not new (Murphy et al., 2000; Dinar et al., 2000 - and, for sequential or 'vertical' decisions, Ostrom and Gardner, 1993; Ostrom et al., 1994b; Cardenas et al., 2011; Holt et al., 2012; Cardenas et al., 2013). Our framed field experiment was conducted with a relevant population who have experienced scarcity of water in irrigation and it is framed in terms of "water" and "irrigation", i.e., not generic "resources". Irrigation is a good setting to study variable scarcity: amounts of water available to farmers rise and fall with rainfall and others' appropriations. We invited farmers from SW Colombia (Campo Alegre in Huila), where intra-annual water variation in irrigation is familiar. We randomly assign each farmer to a group of five and a place on that group's 'canal': places set the order of extraction; and the amounts extracted determine payment. Our treatments differ in sequence: 'from low to high' features four rounds each of 20, then 60 , then 100 units, while 'from high to low' reverses that, featuring 100 , then 60 , then 20 units. For isolating effects of the past, our cleanest comparison is 60 -units-after-20 versus 60 -units-after-100. For 100 (or 20) units, we also look for effects of being faced after 20 (100) and 60 units, instead of first.

We find that upstream farmers extract more - but a lower share when facing higher resources. Further, upstream takes a larger share of higher resources if they have faced lower resources in the past in our earlier rounds, versus when facing higher resources in the initial rounds. The latter result is more consistent with a fall in the weight on others - given high past scarcity and its effects on past behavior than a fall in one's own benefit, though our experiment is not sufficient to identify this as a mechanism. Downstream farmers suffer further, we find, because mid-stream appropriators take higher fractions of available water when upstream extracts more. Such negative dynamics may be significantly magnified in collective settings which feature reciprocal decisions, as is typical within the maintenance of institutions. Our results suggest that having faced scarcity jointly in the past can erode the basis for collective action. Thus, for the building of new institutions, timing vis-a-vis scarcity could affect the probability of success.

The rest of the paper proceeds as follows. Section 2 briefly describes some relevant literatures, while Section 3 summarizes contrasting theories. Section 4 provides background on the site in Colombia for these experiments and presents our experimental design, as well as our sample plus simple statistics. Next, Section 5 conveys our results, after which Section 6 summarizes and provides further discussion.

\section{Literature}

We briefly describe four relevant literatures. The first focuses on roles of scarcity in generating conflicts. The second uses experiments to study resource scarcity. The third is experiments about vertical settings. The fourth is dictator games focused on effects of endowment differences or having multiple recipients.

\subsection{Resource Scarcity E' Conflict}

A literature mainly from political science considers the roles of renewable resource scarcities as one factor that affects the generation of environmental conflicts, peace, and development (Homer-Dixon, 1991, 1994, 1999; Libiszewski, 1992; Schnaiberg, 1994). ${ }^{4}$ Some recent studies challenge such connections and suggest that more empirical evidence is needed to understand roles of resource scarcity in violent conflicts (Meierding, 2013). They call for more attention to describing

\footnotetext{
${ }^{4}$ Environmental conflicts can also be triggered by asymmetries in power relations, divergent attitudes toward the resources (Bob and Bronkhorst, 2010), institutional factors (Timura, 2001; Hagmann, 2005; Gleditsch et al., 2013; Bernauer et al., 2012), and control of valued market (mainly non-renewable) resources such as mineral, metals, oil and others (Schwartz et al., 2000).
} 
relationships between scarcity and conflict in small-scale situations (Theisen et al., 2013).

For water, some studies suggest that scarcity itself is not a principal driver of conflict (Theisen et al., 2013; Bogale and Korf, 2007) but that when it is associated to power relations, production process or political factors it can be one factor within conflicts and disagreements (Glaser et al., 2013). Analyzing the effect of scarcity and variability on irrigation systems also requires consideration of scarcity's effects upon local forms of organization, cultural patterns and asymmetries (see Reuveny and Maxwell (2001)).

\subsection{Resource Scarcity Experiments}

The effects of resource scarcity have been explored using experiments in the lab and in the field. Here we briefly recount some results. Rutte and Wilke (1987) report less extraction if resources are scarce. In addition, they find that 'endogenous shocks' induced by human behaviors have less effect on individuals' propensities to extract than do exogenous shocks in resource scarcity. Fischer et al. (2004) find that when a common-pool resource regenerates faster - lowering scarcity on average its users reduce extraction. In seeming contrast, MorenoSánchez and Maldonado (2010)'s semi-dynamic common-pool experiment finds that moving from a higher to a lower resource level (raising scarcity) reduces the rate of extraction. We note that this does not necessarily contradict the prior result that raising scarcity reduces extraction. In Ostrom's non-monotonic relationship between resource scarcity and resource extraction these results concerning changed scarcity fit for different initial scarcities: moving from zero scarcity to some scarcity could reduce extraction; while moving from some scarcity to a higher scarcity could increase extraction.

Osés-Eraso and Viladrich-Grau (2007) and Osés-Eraso et al. (2008) use a repeated simultaneous appropriation experiment where initial resources are determined by nature but over time it is the individual appropriation decisions that determine resource availability and depletion. Their between-group design considers different levels of scarcity (abundance, some scarcity, and more extreme scarcity) and their results suggest that an increase in the initial resource scarcity leads to lower absolute extraction yet such shifts are not enough to avoid resource depletion. Abundance increases the frequency of 'full' extraction (i.e., the dominant self-interested strategy) while reducing zero extraction. Blanco et al. (2015) replicates this in the field, adding within-group stock changes. They find, in contrast, that scarcity increases extraction depending upon the initial level of that scarcity: users take time to reduce the level of extraction when the resource level is moderate; but immediately extract more when the resource decreases to a fulldepletion stage. Again scarcity's effect is nonlinear.

D'Exelle et al. (2009) use a repeated, framed distributional experiment in Tanzania to consider allocations of water between upstream and downstream users with exogenous determination of abundance/ scarcity and a production threshold that yields efficiency-equity tradeoffs. After decisions have been made by upstream users, downstream users can react with different forms of communication or punishment. Equal sharing is always the mode, even though it causes efficiency loss. Under higher scarcities, though, upstream users on average extract more - yet are more likely to rotate who receives a share above the production threshold. Based upon the same evidence, Lecoutere et al. (2010) point out that not all of these water users reacted to water scarcity in the same way, highlighting that poorer participants are most likely to react to water scarcity with selfish appropriation behaviors.

\subsection{Sequential (or "vertical") Setting Experiments}

Several theoretical and empirical analyses - including but not limited to experimental analyses - addressed asymmetric access to common-pool resources, such as in watersheds or irrigation systems in which some actors are 'farther down the line'. Early work by Ostrom focuses on the idea that challenges in, e.g., irrigation can be overcome via effective institutional designs - if users see mutual dependencies. For instance, upstream users might need downstream users to make investments in order to sustain the entire system (Ostrom and Gardner, 1993; Ostrom et al., 1994a) - not necessarily true for watersheds (see Holt et al. (2012) utilizing laboratory experiments).

Recent field experiments (Cardenas et al., 2013) suggest that even if the design of an institution does not improve efficiency, it may still generate what is considered an improvement in distribution. These experiments involved two stages. In the first, the individuals invested in a public fund which established the magnitude of an initial water stock. That stock was then distributed, in the second stage, through sequential appropriation decisions that are taken following the run of an irrigation canal. Given low contributions by the downstream users, who are receiving lower appropriations, the authors say that a vertical distribution of common resources can distort water provision, i.e., these investments, away from the social optimum (see Cardenas et al. (2011)). Within our experiments, users do not have such mutual dependencies and water stock is determined by an exogenous shock.

\subsection{Dictator Game Experiments}

Our design is, essentially, a sequence of dictator games. The literature has explored the effects of different stake sizes (Bolton et al., 1998; Forsythe et al., 1994; List and Cherry, 2008; Carpenter et al., 2005; Ockenfels and Werner, 2012) and finds offers below equal splits, with average giving of $20-30 \%$. Most of these studies use a betweengroup design in which a dictator does not face a shift in stake size, as in our design. Most studies find no significant change when the stake size is increased (Forsythe et al., 1994; List and Cherry, 2008; Bolton et al., 1998; Carpenter et al., 2005; Ockenfels and Werner, 2012).

Another branch of the literature explores the effect of having more than one recipient affected by dictators' decisions (which is the case in our vertical setting). While mixed results have been reported (Brañas-Garza, 2006; Stahl and Haruvy, 2006; Andreoni, 2007) and not all results are directly comparable, a recent meta-analysis concludes

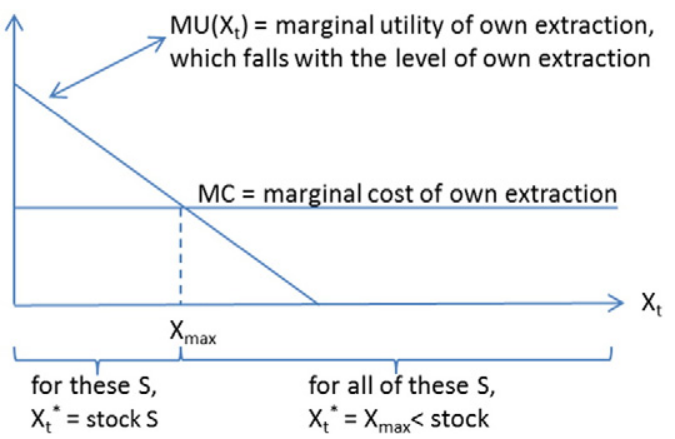

Fig. 1. Typical predictions from diminishing marginal utility of own extraction (without other-regarding preferences). 

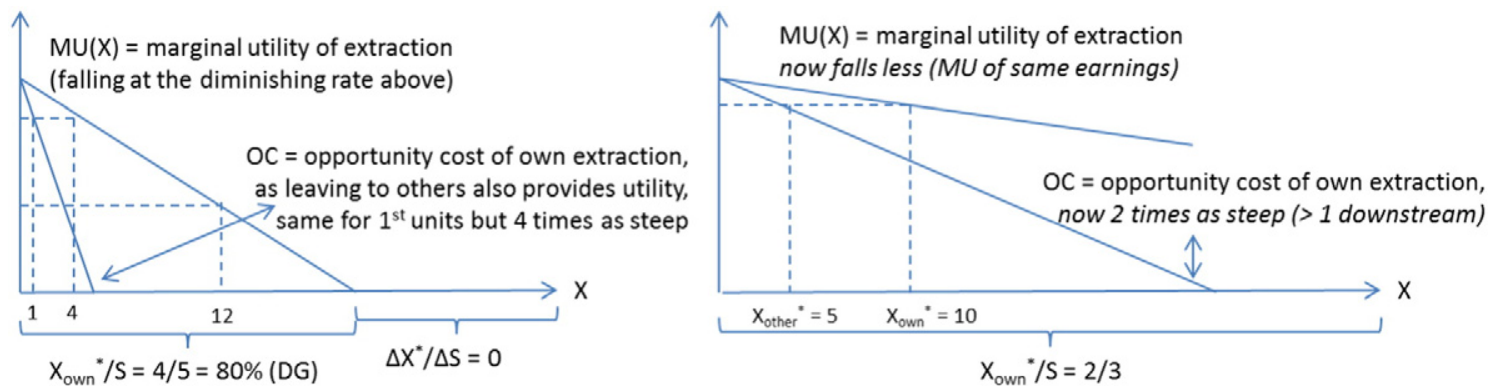

Fig. 2. Marginal cost here is not direct cost of extraction but opportunity cost since each unit taken lowers what others can have.

"if there are multiple recipients, generosity goes up by more than $10 \%$ " (Engel, 2011, p.607). That is consistent with, for instance, Charness and Rabin (2002), who do a series of one-shot Dictator Games, some with one and some with two recipients. In their design, dictators have only two options to choose between - an even distribution and a uneven distribution - and the number of recipients did matter to the decisions. When there were two recipients, the dictators chose the even distribution $60 \%$ of the time, which is a significant difference from the games in which there is only one recipient (like the classic Dictator Game), where the even distribution was chosen only $38 \%$ of the time.

\section{Theory}

Given mixed empirical evidence, we consider conceptually how scarcity should matter. In particular, we would like to have models of path dependence with predictions of durable impacts from past scarcities.

\subsection{Underlying Assumptions (Diminishing Static Own Marginal Benefits E Scarcity)}

Before considering any dynamics, we start by reviewing a few static predictions of scarcity's impacts. We emphasize that some scarcity is required for anybody to help others by restricting own appropriation; as Ostrom, 2009a notes, without scarcity, nobody else's welfare will be affected by one's own extractions. ${ }^{5}$ Put another way, 'abundance' - sufficient resources that extraction by one implies no costs for others implies that there is no reason for people to incur costs, either individually or within a collective action, to increase others' access to resources. Everyone should extract until own marginal benefits are equal to marginal costs, as there is no opportunity cost of extraction even if one has otherregarding preferences (seen in Fig. 1 for concave utility, i.e., diminishing static own marginal benefit of resource extraction). This predicts complete extraction equal to the stock $(\mathrm{X}=\mathrm{S})$ for low stocks, then falling $(\mathrm{X} / \mathrm{S})$ as stock rises.

Our experiment has no marginal cost of extraction but instead scarcity. That implies an opportunity cost, if one has other-regarding preferences, since with scarcity each unit extracted reduces what others take. Fig. 2's left graphic assumes this 'other-regarding opportunity cost' (or OC) falls more steeply with the amount extracted by others than does the marginal utility of extraction with one's own extraction (MU). Since the OC for the first unit others extract has the same value as the MU for the first unit one extracts, there is no stock that one takes completely for oneself. To maximize one's MU plus OC, given the slopes one should take 4 units for every 1 unit left for others - consistent with results of classic Dictator Games.

Concavity could arise from lower earning per unit of extraction but in our experiment the dollars earned per unit X extracted are constant. Thus, here, we could assert a falling marginal utility per dollar earned

\footnotetext{
${ }^{5}$ Araral (2009) cites others and examines scarcity plus other factors affecting collective action in Filipino irrigation associations.
}

but for this relatively small range of earnings, we should assume a lower rate of fall in marginal benefits. Further, our experiment features multiple others downstream of most upstream actors. From literature about Dictators facing multiple recipients that could raise the weight one accords to the set of all others. Fig. 2's right graphic conveys both these changes as again any stock will be shared in some degree but driven by flatter MU and flatter OC. As OC is now relatively less steep, own extraction of any $\mathrm{S}$ is lower. ${ }^{6}$

For MU and OC above zero, Fig. 2 predicts the share that one takes is not affected by the stock's size. However, such an OC line might actually start lower down the axis, in addition to having a steeper slope. That is, it seems perfectly plausible that not only might one's perception of gains from others' extraction fall more rapidly with their extraction than do one's own benefits but also the value for the first unit that others consume might give one less happiness than one's own marginal utility from one's own first unit. Fig. 2 then would predict that one extracts all units up until one's MU has fallen to others' initial OC. Put another way, it would predict that, as stock rises, own extraction would be a falling share of stock.

\subsection{Dynamics (Roles of the Past) For Own Marginal Benefits}

Fig. 3's left graphic adds a 'reference point', from Tversky and Kahneman, 1986's utility model, to consider variation in current extraction for a fixed past scarcity. This supports Fig. 1's perspectives. The reference-level idea is that people adapt, renormalizing their preferences to the current situation or 'reference point', and then evaluating any change relative to it - placing steeper costs on having losses. ${ }^{7}$ Holding past scarcity constant, to the left in Fig. 3, confirms Fig. 1's perspective upon scarcity and own marginal benefits: for low past extraction $\mathrm{X}$ from low past S, as per Figs. 1 and 2, a larger $X$ gain from high current $\mathrm{X}$ implies lower own marginal benefits than a smaller $\mathrm{X}$ gain, from medium current $\mathrm{X}$.

Such a reference-point model also generates a prediction for the impacts of past scarcity levels. Fig. 3's right graphic holds current extraction fixed while considering varied past extraction levels (the result of varied past scarcity levels if the predictions of Figs. 1 and 2 are to be believed, even roughly). If people evaluate current extraction relative to the past, then past scarcity clearly should matter, since the same medium current extraction implies a gain after high levels of extraction but a loss after lower. Given that, Tversky and Kahneman (1986)'s claim that utility is more sensitive to losses will matter here. Fig. 3's right graphic highlights that this predicts a lower own marginal benefit after higher scarcity. Thus, appropriators are predicted to be less focused on themselves when the past scarcity was higher.

\footnotetext{
${ }^{6}$ We consider a single period but in a multi-period setting this could be about expected scarcity. Grossman and Mendoza 2003 (p.757), e.g., conclude that "anticipated future resource abundance increases the incremental value attached to survival (...)".

${ }^{7}$ An additional specific assumption they make is risk aversion for gains but risk-loving preferences for losses. That is important and is truly distinct from standard neoclassical risk aversion. However, for considering scarcity, that difference is not our focus.
} 

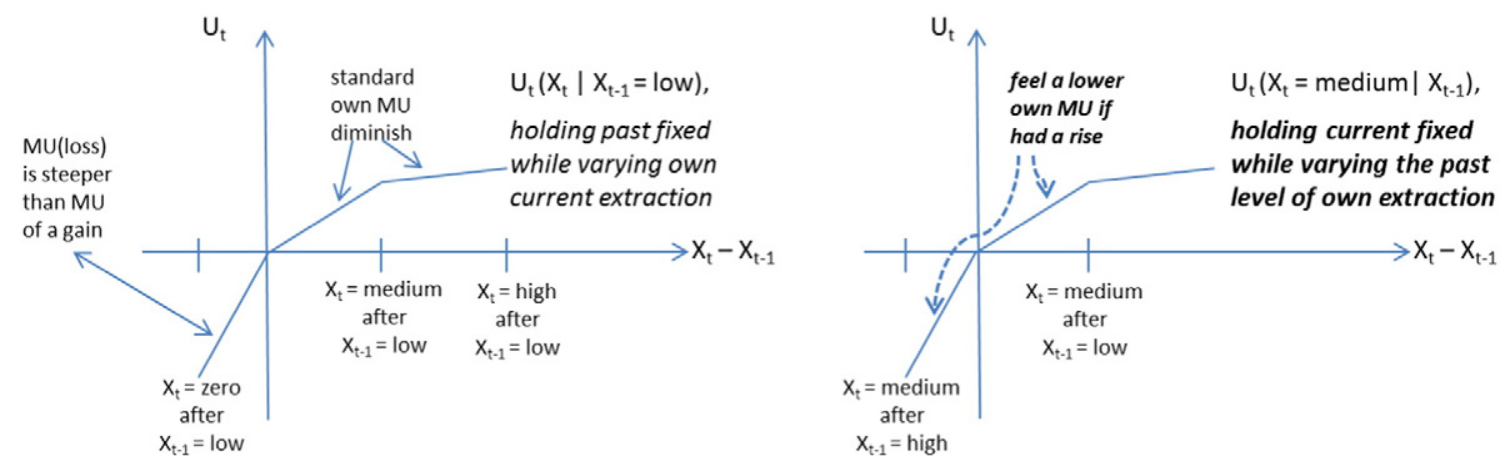

Fig. 3. Reference point (Tversky and Kahneman, 1986) implies own marginal utility of extraction reduced by high past scarcity.

Making that more explicit for our setting, Fig. 4's left graphic depicts lower own benefits, i.e., shows the impact of lowering the gains from own extraction (upon a setting like Fig. 2's right graphic). For any given other-regarding OC, quite clearly this predicts a lower share of extraction from any stock $\mathrm{S}$.

\subsection{Dynamics for Other-Regarding Opportunity Costs (Based on Others' Benefits)}

An alternative, endogenous-preference model focuses upon otherregarding marginal benefits. ${ }^{8}$ Per our static perspective, initial high scarcity discourages self-restriction - so that little is left for others. To this we add a psychological reaction to, e.g., the tension between own and other-regarding benefits: to feel better about providing little for others, one might simply decide that they did not deserve much. ${ }^{9}$ As in Fig. 4 's right graphic, one could simply lower the weight placed upon gains in others' extraction (and, as noted above, while that could mean a steeper slope, it could also imply a lowered intercept). ${ }^{10}$

This predicts the opposite of above, i.e., less self-restriction if past resource scarcity was higher. The reason for the contrast is that, following higher scarcities, what has shifted is how one treats others. Here, instead of lowering one's own reference level, and thus by implication one's own marginal benefit, to rationalize past poor treatment of others one 'renormalizes' downward the value placed upon others. That is consistent with "cognitive dissonance", although our experiment cannot identify the mechanism. In sum, Fig. 4's right graphic predicts less selfrestriction when the past resource scarcity was higher.

\section{Field Context, Experimental Design and Our Sample}

\subsection{Field Context: Water Availability \&' Local Institutions}

Campo Alegre is in the Neiva River basin, in a highly dry area of Huila Department in SW Colombia. The river originates in Algeciras municipality, in the eastern mountains, and flows into the Magdalena River. It has about 1300 direct users in 48 irrigation districts, which are oriented around productive purposes - mainly growing rice. Each has a water intake from the river into its main canal. The water is distributed within each of the districts using canals from the main canal to the crops. The

\footnotetext{
8 More generally, preference endogeneity has been considered in various ways in behavioral-and-experimental literature, e.g.: Charness and Rabin (2002) considers why people turn spiteful; Bowles (1998) considers effects of interactions in communities; and Henrich et al. (2001) considers differences in pro-social choices in field experiments across more or less isolated societies.

9 Examples are widespread. Drawing on quite different literatures on demonizing the oppressed (see Mayer (forthcoming)) for example Slotkin (2000) documents captivity narratives depicting Native Americans as savages, Dittmer (1977) says that rape narratives in the Jim Crow South helped to legitimize increasingly repressive laws, and Nazis blamed Jews as agents of Germany's downfall.

${ }^{10}$ Festinger (1957), Zimbardo (1969), Aronson (1976) and Konow (2000) say people shift beliefs to alleviate cognitive tensions. We will not attempt to spell out a psychological theory here but instead rely on such literature for the idea of this kind of shift.
}

number of users within a district ranges from 40 to 100 and conflicts over access to water to irrigate are common in these districts (Velez et al., 2011). Two principal reasons for such water-management conflicts are: first, scarcity in dry periods (between June and September); and second, weak local institutional frameworks.

By law, formal rules to manage the use of water from the Neiva River are established by a local environmental protection and control agency "CAM" (Corporación Autónoma del Alto Magdalena). The resolution 3660 (December 26, 2007) defined water quotas for each one of the 1300 Neiva River users. The amounts were based on production area and type of crop or use reported. Calculations were made for average needs - but the local authority cannot assure water availability for all users in drier periods. Specifically, to define average supply, CAM used data from 1967 to 2003 (Fig. 5) and 8356 l/s (483 l/s below average supply) was designated for distribution among direct users. The remaining water is for ecological flow, canal upkeep and users not included in the regulations. Reported demands for all productive uses is about 13,216 l/ $\mathrm{s}$, meaning that the supply is about $63 \%$ of the demands that have been formally recognized; thus, it is very clear that in time the region will face water scarcity. More specifically, the Neiva River is characterized by relative abundance in rainy seasons but shortages during the summer. Recently, shortages have intensified because summer periods are longer and drier.

High dependence on the Neiva River alongside asymmetry in access and increasing uncertainty has challenged institutions. Compliance is low for payment of 1730 pesos ( 0.90 US dollar) per liter/second, noting that is independent of weather conditions so users sometimes pay for water they do not receive. The implementation of regulations also falls short per allocations. While CAM in principle verifies water removals from each canal, since the implementation of quotas only twice have verifications taken place. Therefore, the users do not trust CAM's controls and most do not comply with the payments or quotas.

Of the 48 irrigation districts, only one is managed by a communitarian organization (USOIGUA, for users of the Iguá canal or Neiva River Tunnel). It has 89 members and oversees total 132 land plots. This district also happens to enjoy a privileged position, as it is the first one upstream in the Neiva River. The irrigation district covers 1762 acres, of which 1066 are arable land. Consistent with the assertion of CAM's limited influence, allocation within this district is defined by a local communitarian organization.

This setting is similar to various cases in "the commons literature", in which a shared watershed provides water to several irrigation systems. In particular, it shares some characteristics with irrigation systems in Nepal described by Benjamin et al. (1994), Lam (1998) and Shivakoti and Ostrom (2002). However, Campo Alegre also differs in combining community with state rules for the management of one system. Most case studies, including for Nepal, focused on one type of management. For example, Ostrom (1990) studied successful systems managed by community institutions in the Philippines and in Spain created in reaction to periods of water scarcity, as well as failed state-managed irrigation systems within Sri Lanka. 

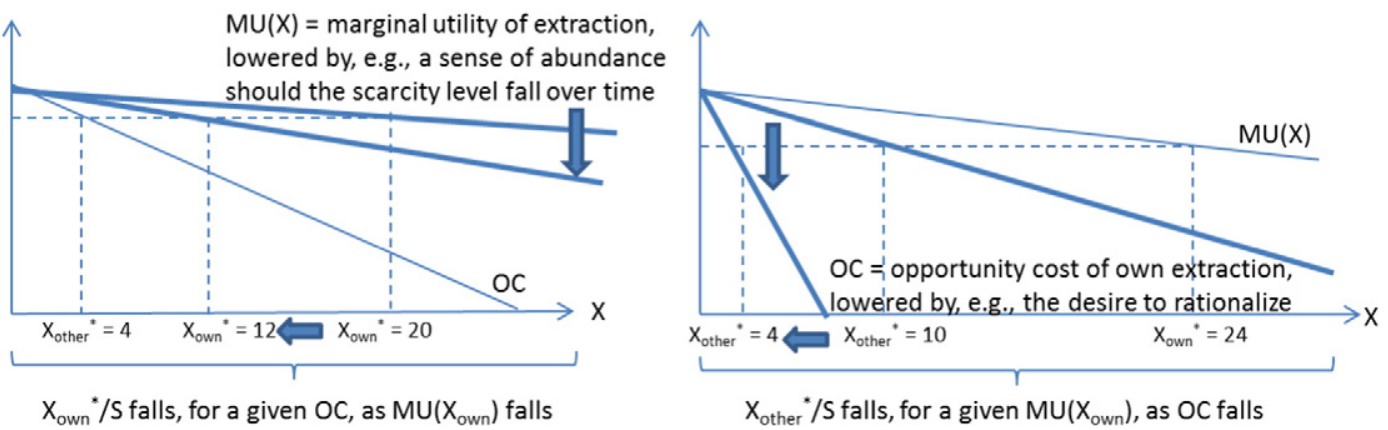

Fig. 4. Reducing one's other-regarding opportunity cost instead of reducing own marginal utility of extraction.

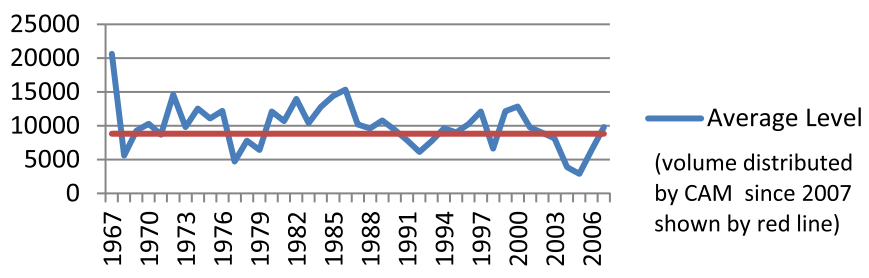

Fig. 5. Average yearly volume (1967-2006) versus volume distributed by CAM.

\subsection{Experimental Design}

Following the appropriation stage of an irrigation game by Cardenas et al. (2011), we developed a framed field experiment with asymmetric access, i.e., in a sequential setting of exogenous water supply. We randomly assign each participant to a group of five and to a position $(A, B, C, D, E)$ on the group canal. Positions set the extraction order (Fig. 6). Each participant knows her position but not anybody else's.

At the beginning of each of our 12 rounds, each participant receives five units of water directly. This is called rainfall and cannot be redistributed. Then, in each round, additional water from the canal is available to extract. Participants are informed that this initial amount of water could vary across rounds but nothing about expected direction of change, i.e., whether amounts will increase, decrease or both. The initial amount of water - i.e., the amount that arrives to position $\mathrm{A}$ - is announced to all the players. Player A allocates the amount between herself and downstream, i.e., everyone downstream as a whole. All players are informed of the water remaining after A's extraction then B decides how much to extract. This procedure continues down to the final position $\mathrm{E}$ (where all the rest of the water should be taken ${ }^{11}$ ). We note that there are no carryovers of water across rounds, cumulative savings or cumulative deficits.

Communication among players is never allowed. While any participant is making a decision, all of the other participants are writing down the amount that they think the participant is going to extract. This procedure helps to protect each participant's identity, since everybody is always writing something, while also providing a helpful way of measuring participants' expectations (something that is challenging to measure outside of experiments). Thus monitors pick up a decision sheet from everybody, though only one participant has made that decision regarding how much water to take from the irrigation canal.

We implemented two treatments, i.e. different orderings of the same three levels of scarcity. Treatments were randomly assigned by session. This was unknown to all the participants, each of whom was aware only

\footnotetext{
${ }^{11}$ In fact, sometimes players $\mathrm{E}$ do not take all the water. That does not help other players yet anecdotal evidence suggests that E players leave water to "birds" or "the watershed". As Cardenas and Ostrom (2004) argue, this may mean participants bring information to games, deciding in part on dimensions of group and institutional context, plus information about themselves.
}

of the single treatment to which she was assigned. The treatments differ in their orders of the resource scarcities faced by participants: the treatment 'from low to high resources' involves four rounds of 20 units, four of 60 units, then four of 100 units of water; while 'from high to low resources' reverses that ordering, i.e., it features four rounds each of 100 , then 60 , and then 20 water units. Our experimental design implies that the level of resource scarcity varies for every participant, i.e., that each participant faces each scarcity level. We do not face different people with different scarcities and, because we have randomized which participant faces which specific ordering of all these scarcity levels, we should not be confounding treatments with any participant characteristics. We are comparing across randomly chosen treatment groups, i.e., across subjects, but comparing average within-subject changes.

Participants' earnings in a given round depended upon the total number of units of water that they had extracted during that round. Units of water are worth 100 pesos, so the earnings per round are 100 * [5 units rainfall + \# units extracted in round]. Payments are based on the sum of all of the rounds. Each session had at least two groups of 5 players and we had a maximum of 30 players (i.e., six groups). We did not tell players who their group members were and all subjects were asked to remain silent.

Subjects played one practice round, to start, to familiarize themselves with the forms and game. Regardless of the treatment randomly selected, the resource level in that practice round always was 50 . Thus, while in the dynamic theories above in principle a variation in resources across the practice rounds could have had durable impacts upon the later rounds that determined participants' payments, there was no variation in practice-round resource levels that can explain our estimated treatment effects (and we could imagine that, if anything, facing 50 before each treatment might limit our treatment effects). Assistants helped with reading and writing but participants made their own decisions, which assistants transcribed as needed. Each session lasted about three hours, including practice and payment in private.

\subsection{Our Sample}

In total 320 people - evenly divided by treatment - participated during March 2011 or September 2012. With 12 rounds of decisions made by each person, for each of the two treatments there would be 1920 observations - although we hasten to emphasize that they would not all be independent observations (that fact is reflected in the clustering that we employ for the regressions underlying our tables below). In many rounds, however, all of the water was taken before Player E, and sometimes before Player B. ${ }^{12}$ In total, we observed 1108 extraction decisions for 'low to high' and 1213 for 'high to low'. Those values already

12 Of Players A, 7 extracted all the water in all rounds, leaving 28 participants without a chance to extract. Other individuals took all of the water that arrived at their locations some each from Players B, Players C and Players D. As a consequence, overall 80 participants never got a chance to extract: $8.75 \%$ were Player B; $15.75 \%$ Player C; $28.75 \%$ Player D; and $43.75 \%$ were Player E. 


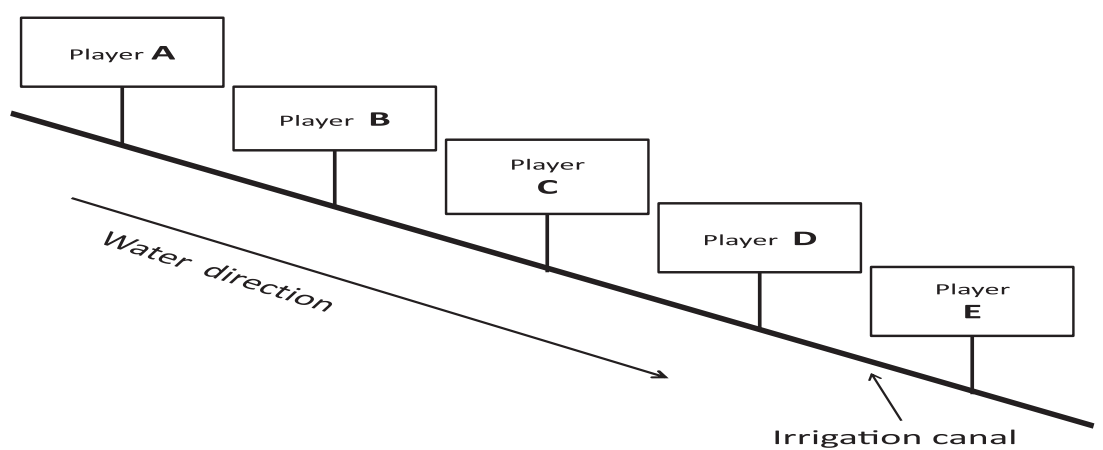

Fig. 6. Sequential (or 'vertical') Extraction Setting Along Canal.

provide a first indication that our treatment has impact: it appears that extractions are less likely to be other-regarding, concerning the rest of the canal downstream, when the low resources come first. That supports a lowered weight on others (consistent with 'cognitive dissonance'), more than lowering own marginal benefit, as a model for path dependence (i.e., effects of past scarcity on current behavior).

Earnings covered the full range, from rainfall earning alone if all water has been taken by others, which yields 6000 pesos $=100$ pesos * $(5$ rainfall units * 12 rounds), to when A extracts all of the water, yielding 78,000 pesos $=100$ pesos $*[(5$ rainfall units $* 12$ rounds $)+4$ rounds $*$ $(20+60+100$ units)]. The average was 20,321 pesos, close to the opportunity cost ( 20,000 pesos) of daily work in this area.

Our full sample's average characteristics are shown in Table 1. The majority of the participants were men (83\%). Average age was 43 years old and average education was 7.2 years. Most participants in the experiment worked in agriculture activities, with only $23 \%$ of the sample owning land themselves. Recalling that Usoigua is run by a communitarian organization, and that it is located first along the river, we also provide statistics separately for those who live and work in Usoigua (and in addition, tests which compare statistics for Usoigua against the whole sample). Differences are discussed in the next section.

\section{Results}

We present basic statistics then regressions for participants' choices, followed by checks on robustness.

\subsection{Extraction Patterns}

Fig. 7's trajectories show the average water arriving, plus fractions taken - by players, treatments and resource levels. The top panel shows our 'high to low' treatment, i.e., 100, 60, then 20 units of water. Its upper-left box is for 100 units of water in Rounds $1-4$. Such sequential settings clearly disadvantaged the appropriators further down the canal as Players A-D each took over half of the water that reached them. As each actor is effectively a dictator, versus all those downstream, we note that half is far less than the typical $80 \%$ for classic Dictator Games, perhaps not surprising with multiple actors downstream of A-C. That holds in the upper center (right) for 60 (20) in Rounds 5-8 (9-12) too, as well as in the lower panel. ${ }^{13}$

Looking across Fig. 7's top panel also suggests that for higher initial resources, i.e., to the left, players extract a lower fraction of the arriving water. That is consistent with falling net marginal benefit. That panel also shows that absolute extractions fall when initial resource level is smaller, suggesting that some consideration of others is part of net thinking (some is clear, since most extraction is under 100\%).

One additional speculation from these raw extraction values is that more seems to be extracted in the lower-right box (100 units for 'low

\footnotetext{
13 One of our Players E actually stormed out of a session, upset at having been treated so poorly by the Players A-D upstream.
}

to high') than in the upper-left box (100 units for 'high to low'). That is suggestive of an effect of the ordering of scarcities, along the lines of our hypotheses of interest. While it could reflect some "learning" effect, i.e., higher extraction for any scarcity level that comes last, by contrast extraction looks similar in the lower-left and upper-right boxes for 20 units (see below within Table 4 that we show clearly there is no single pure "learning" effect in terms of when a scarcity occurs; further, Table 3 controls for any such effect by comparing the four rounds for a given level of resources).

Scarcity is not confounded with ordering at all in comparing Fig. 7's central (or 60-unit) boxes, since those are always in Rounds 5-8, i.e., have the same timing within the different scarcities orderings. Comparing those boxes if anything might also suggest greater extraction for the 'low to high' treatment. Yet the differences are small and we will use regression below to control for other factors in comparing.

Table 2 provides another way to describe raw extraction patterns, again emphasizing the critical role of farmers' positions along vertical canals. Here we see how often any water arrives at each farmer, in light of for instance the fact that observed earnings included the maximum for A from taking all water. We see that - impressively in a fashion - Player A has taken all of the water units about $20 \%$ of the time, demonstrating no other-regarding preferences at all (thus we have heterogeneity along that dimension). We also see here differences across boxes that support the conjectures above, based on Fig. 7 boxes. For instance, comparing 60-unit boxes finds higher fractions of water nonarrival within the 'low to high' and comparing 100-unit boxes shows considerably higher water non-arrival (to D-E) in the 'low to high'.

Next we subject these descriptive results to further scrutiny using regressions, for which rounds are clustered by player (since we should not treat multiple rounds for the same player as independent). Given that our focus is the distributive outcomes generated by sequential extraction along each 'canal', within regressions we focus on extraction by Players A, B, C and D (those with somebody downstream). We test for treatment impacts while controlling for effects of other possible determinants of behaviors. We study Players A separately, as their extractions are the only ones that do not follow prior extraction. We study Players B with C and D yet also report separate regressions for each of these distinct positions.

\subsection{Treatment Effects Upstream (Players A)}

Table 3 conveys regression results for Players A (column 1), as well as for Players B, C and D (column 2), and then - breaking down column 2 - for each of Players B (column 3), C (column 4), and D (column 5). Since we want to be able to compare the same dependent variable across different levels of resources, we consider the fraction extracted by each participant from the units of water arriving at her position. ${ }^{14}$

\footnotetext{
${ }^{14}$ Canonical results from resource-division experiments suggest that shares are one way people consider others versus oneself.
} 
Table 1

Sample average characteristics.

\begin{tabular}{|c|c|c|c|c|c|c|c|c|c|}
\hline & $\begin{array}{l}\text { Gender } \\
(\mathrm{M}=1)\end{array}$ & $\begin{array}{l}\text { Educ. } \\
\text { (years) }\end{array}$ & $\begin{array}{l}\text { Owner } \\
(1 / 0)\end{array}$ & $\begin{array}{l}\text { Age } \\
\text { (years) }\end{array}$ & $\begin{array}{l}\text { Income } \\
\text { (ranges*) }\end{array}$ & $\begin{array}{l}\text { \# people know } \\
\text { in the session }\end{array}$ & $\begin{array}{l}\text { \# groups in } \\
\text { the session }\end{array}$ & $\begin{array}{l}\text { \# individuals } \\
\text { in the session }\end{array}$ & $\begin{array}{l}\text { Usoigua } \\
(1 / 0)\end{array}$ \\
\hline All & $83 \%$ & 7.2 & $23 \%$ & 43 & 1.9 & 6 & 3 & 320 & $5 \%$ \\
\hline Usoigua & $67 \%$ & 6.8 & $47 \%$ & 49 & 2.1 & 6 & 4 & 15 & $100 \%$ \\
\hline Ranksum Test Pvalue (all-Usoigua) & 0.08 & 0.69 & 0.03 & 0.07 & 0.35 & 0.35 & 0.56 & NA & NA \\
\hline
\end{tabular}

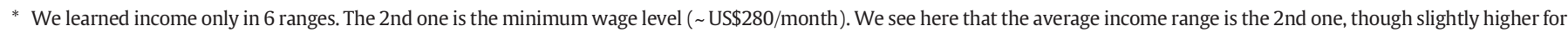
those who live and work in Usoigua.

We consider many independent variables, including round (and see varied specifications below in 4.4).

We feel it is simplest to interpret specifications in which each resource level, in each treatment, is a dummy. Our two treatments vary in which level is faced first, 20 ("First $=020$ ") or 100 ("First $=100 "$ ). For each treatment we have the same three levels of resources ("Units $=020$ " "Units $=060$ " "Units $=100$ "). That generates six such dummies, of which we omit one ("Units $=100$ When First $=100$ "), thus coefficients are relative to the omitted case. Some tests of interest are in Table 3 (parentheses are standard errors), while other questions require tests of equality across coefficients (we report those tests, with p-values).

We focus first upon upstream extraction, i.e., behaviors by Players A, analyzed in the 1 st column. Its first row focuses directly upon our leading hypotheses, since its coefficient compares 100 units when the initial resource level is 20 with 100 units when initial resources equal 100 , i.e., the omitted category. Thus, this row tests whether starting with highest scarcity early changes the fraction extracted from 100; put another way, for a given resource level this tests whether the ordering of the scarcity levels matters. It does upstream, for Players A. The coefficient indicates that extraction rises by $14 \%$. That is significant, at $10 \%$, and is positive, consistent with a lowered weight on others (e.g., a cognitive dissonance model): having faced high scarcity, and on average allocated less water to people downstream (facts in Fig. 7 and Table 2 confirm this), to justify that past choice one may lower one's weight on those downstream.

Higher extraction following higher early scarcity is also suggested by Player A's next two rows for when resources were 60 . The coefficient for First $=020$ is almost three times the coefficient for First $=100$ (implying a positive coefficient if, for 60 , we were to test a treatment
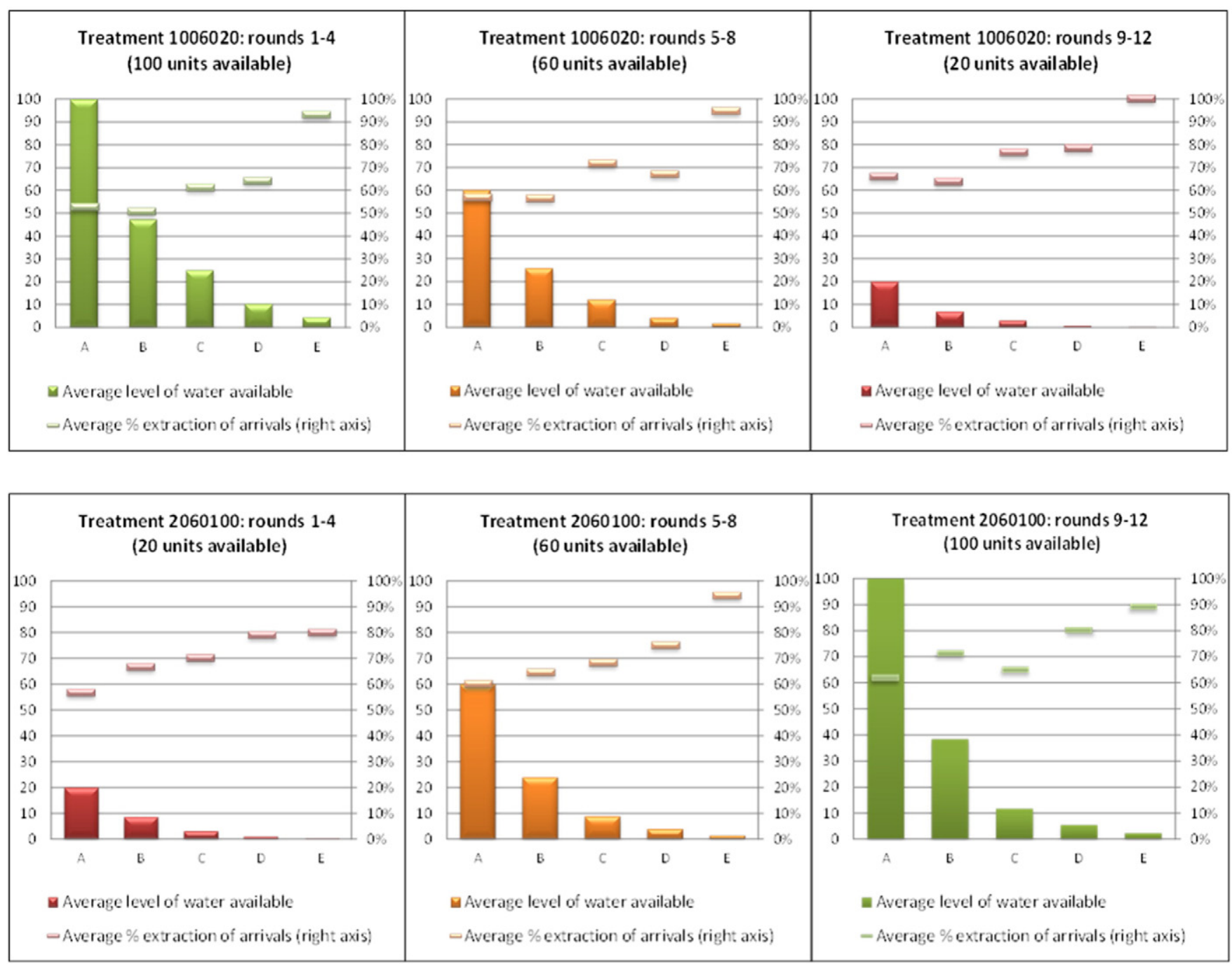

Fig. 7. Average level of water available and \% extraction of arrivals by treatment and stage. 
Table 2

Statistics by round (by quantity/ordering).

\begin{tabular}{|c|c|c|c|c|c|c|c|c|c|c|c|}
\hline \multicolumn{4}{|c|}{$\begin{array}{l}\text { Average extraction level (rounds 1-4) } 100 \text { units } \\
\text { available }\end{array}$} & \multicolumn{4}{|c|}{ Average extraction level (rounds 5-8) 60 units available } & \multicolumn{4}{|c|}{ Average extraction level (rounds 9-12) 20 units available } \\
\hline Player & $\begin{array}{l}\text { \# total obs. } \\
\text { (participants } \\
\text { *rounds) }\end{array}$ & $\begin{array}{l}\text { \# obs. when } \\
\text { water available }\end{array}$ & $\begin{array}{l}\text { \%obs. when } \\
\text { water was } \\
\text { depleted }\end{array}$ & Player & $\begin{array}{l}\text { \# total obs. } \\
\text { (participants } \\
\text { *rounds) }\end{array}$ & $\begin{array}{l}\text { \# obs. when } \\
\text { water available }\end{array}$ & $\begin{array}{l}\text { \%obs. when } \\
\text { water was } \\
\text { depleted }\end{array}$ & Player & $\begin{array}{l}\text { \# total obs. } \\
\text { (participants } \\
\text { *rounds) }\end{array}$ & $\begin{array}{l}\text { \# obs. when } \\
\text { water available }\end{array}$ & $\begin{array}{l}\text { \%obs. when } \\
\text { water was } \\
\text { depleted }\end{array}$ \\
\hline A & 128 & 128 & $0 \%$ & A & 128 & 128 & $0 \%$ & A & 128 & 128 & $0 \%$ \\
\hline B & 128 & 107 & $16.41 \%$ & B & 128 & 106 & $17.19 \%$ & $\mathrm{~B}$ & 128 & 98 & $23.44 \%$ \\
\hline $\mathrm{C}$ & 128 & 91 & $28.91 \%$ & $\mathrm{C}$ & 128 & 83 & $35.16 \%$ & $\mathrm{C}$ & 128 & 63 & $50.78 \%$ \\
\hline $\mathrm{D}$ & 128 & 74 & $42.18 \%$ & $\mathrm{D}$ & 128 & 65 & $49.22 \%$ & $\mathrm{D}$ & 128 & 32 & $75.00 \%$ \\
\hline $\mathrm{E}$ & 128 & 56 & $56.25 \%$ & $\mathrm{E}$ & 128 & 39 & $69.53 \%$ & $\mathrm{E}$ & 128 & 15 & $88.28 \%$ \\
\hline \multicolumn{4}{|c|}{ Average extraction level (rounds 1-4) 20 units available } & \multicolumn{4}{|c|}{ Average extraction level (rounds 5-8) 60 units available } & \multicolumn{4}{|c|}{ Average extraction level (rounds 9-12) 100 units available } \\
\hline Player & $\begin{array}{l}\text { \# total obs. } \\
\text { (participants } \\
\text { *rounds) }\end{array}$ & $\begin{array}{l}\text { \# obs. when } \\
\text { water available }\end{array}$ & $\begin{array}{l}\text { \%obs. when } \\
\text { water was } \\
\text { depleted }\end{array}$ & Player & $\begin{array}{l}\text { \# total obs. } \\
\text { (participants } \\
\text { *rounds) }\end{array}$ & $\begin{array}{l}\text { \# obs. when } \\
\text { water available }\end{array}$ & $\begin{array}{l}\text { \%obs. when } \\
\text { water was } \\
\text { depleted }\end{array}$ & Player & $\begin{array}{l}\text { \# total obs. } \\
\text { (participants } \\
\text { *rounds) }\end{array}$ & $\begin{array}{l}\text { \# obs. when } \\
\text { water available }\end{array}$ & $\begin{array}{l}\text { \%obs. when } \\
\text { water was } \\
\text { depleted }\end{array}$ \\
\hline A & 128 & 128 & $0 \%$ & A & 128 & 128 & $0 \%$ & A & 127 & $127^{*}$ & $0 \%$ \\
\hline B & 128 & 103 & $19.53 \%$ & B & 128 & 101 & $21.09 \%$ & B & 126 & 95 & $24.60 \%$ \\
\hline C & 128 & 78 & $39.06 \%$ & C & 128 & 75 & $41.41 \%$ & $\mathrm{C}$ & 126 & 63 & $50.00 \%$ \\
\hline D & 128 & 52 & $59.38 \%$ & D & 128 & 43 & $66.41 \%$ & D & 126 & 42 & $66.67 \%$ \\
\hline$E$ & 128 & 22 & $82.81 \%$ & $\mathrm{E}$ & 128 & 28 & $78.13 \%$ & $E$ & 126 & 23 & $81.75 \%$ \\
\hline
\end{tabular}

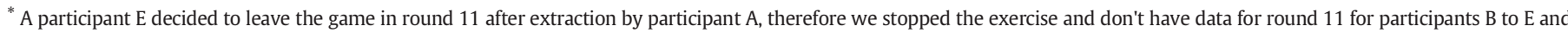
round 12 for participants $\mathrm{A}$ to $\mathrm{E}$.

of a shift to highest early scarcity). However, for Players A we do not possess sufficient data to establish that there is a significant difference across these treatments ( $\mathrm{p}$-value $=0.32$, and that the quantity of data available is an issue within testing is clearly supported below by comparing results for Players B, C and D). Nonetheless even for these data, we can strongly reject the alternative hypothesis based upon a reference-point model that moving from 100 to 60 will lead to higher (less generous) extraction than does moving from 20 to 60. Thus if anything, a lowering of weight on others (e.g., cognitive dissonance model) looks better for comparing at 60 units.

Examining the effect of scarcity's timing or ordering for 20 units again requires testing across the coefficients. Considering first the average of the next two rows for Player A, extraction is higher for 20 (and we note this finding is supported by coefficients for Players B, C and D as well, in the general sense that all are positive and five of the six are significant). That certainly suggests that own marginal benefits matter for extraction, i.e., that at low own benefits generosity is lower. There is no significant treatment effect for 20 , however, because those two coefficients are not different from each other ( $p$-value $=0.48$ ). Since we might expect it to be harder to find an effect with only 20 water units, i.e., less room to adjust, for 20 units we simply note that while such tests are insignificant for B ( $\mathrm{p}$ value $=0.22), \mathrm{C}(\mathrm{p}$-value $=0.65)$ and $\mathrm{D}$ ( $p$-value $=0.22$ ) the signs of the coefficients differences would support lowered weight on others.

\subsection{Treatment Effects Midstream (Players B, C and D)}

That weights on others may fall is also supported, for 100 units, in Table 3's columns for Players B, C, D. The first row for the B,C,D column shows $18 \%$ higher extraction from 100 units when 20 units were first. That is significant at the $5 \%$ level and is positive - high early scarcity raises the fraction that is extracted. The remaining columns, to the right, suggest that this result for midstream is driven by Players B and D.

Considering 60 units, coefficients support lowered weight on others (e.g. cognitive dissonance) and here, for midstream, the difference between First $=020$ and First $=100$ coefficients is significant at $5 \%$ (pvalue $=0.05$ ) for column 2 , which is aggregating the three midstream players. Looking at the columns further to the right, again it is Players $\mathrm{B}$ ( $\mathrm{p}$-value $=0.13$ ) and $\mathrm{D}$ ( $\mathrm{p}$-value $=0.01$ ) who are driving this result (as for Player $\mathrm{C}$ we have $\mathrm{p}$-value $=0.67$ ). We can see that the issue of data quantity is a real one, though, because for instance Player B's substantial difference across the coefficients is significant only at $13 \%$.
We can also see that dynamics include a 'selfishness norm', where midstream mimics upstream. For column 2, and to the right, the fractions extracted by $\mathrm{B}, \mathrm{C}$ and $\mathrm{D}$ are higher when the fraction taken upstream was higher ('upstream' for B means A, for C it means A plus B, for D it means A plus B plus C).

\subsection{Further Covariates \& Specifications}

We have also included here the covariates we believe have reason to potentially influence the results. While some did not have significant impacts, such as education and owner, others did, such as gender. We were concerned that in small sessions people might feel less anonymous and act more cooperative. However, large sessions could raise the chance of knowing somebody, which could lead to cooperation. Thus, we include session size and the number of people you know (note they are positively correlated). We also checked that the dummy variable for which trip to the field generated the data has no effects.

We see that, among the Players A (but not other players), those from Usoigua extracted far less. Such an effect could in principle derive from Usoigua's governance history or pressure to act responsibly as they are located first on the river in reality and, thus, perhaps more feel responsibility in that position. Recalling from Table 1 that Usoigua participants more often were landowners (a significant difference) - whose views might differ from farm laborers' - we note that when the indicator for Usoigua is dropped, Owner is negative and significant. Ownership may be the story (or two meaningful factors are collinear).

Clearly standard OLS is not the right treatment of these data, since we cannot view each round as an independent observation when there are up to 12 decisions for each participant. While clustering by individuals seems sensible, we confirmed that results are robust to using a jackknife. We also checked robustness to ignoring the rounds, i.e., to averaging by resource level for each participant. ${ }^{15}$ Recall that Table 3 controls for round recoded 1-4 within resource level and small positive effects change nothing.

Finally, Table 4 presents some additional robustness checks to directly assess alternative stories. For an alternative approach to simple interpretation, we have broken observations up by resource level,

\footnotetext{
15 Dropping data in this way raises standard errors for treatments, lowering significance for limited N, but confirms all patterns. For 60 units we lose some significance but as in Table 3 we continue to find significant interactions between First and 100 units.
} 
Table 3

Explaining extraction behavior. (OLS, clustered by player, omitting players E, standard errors in parentheses).

\begin{tabular}{|c|c|c|c|c|c|}
\hline LHS $=\%$ extracted & Players A & Players B,C,D & Players B & Players C & Players D \\
\hline Units $=100$ When First $=020$ & $\begin{array}{l}0.137^{*} \\
(0.079)\end{array}$ & $\begin{array}{l}0.178^{* *} \\
(0.049)\end{array}$ & $\begin{array}{l}0.243^{* *} \\
(0.074)\end{array}$ & $\begin{array}{l}0.078 \\
(0.095)\end{array}$ & $\begin{array}{l}0.211^{* *} \\
(0.083)\end{array}$ \\
\hline Units $=060$ When First $=100$ & $\begin{array}{l}0.041 \\
(0.038)\end{array}$ & $\begin{array}{l}0.052^{* *} \\
(0.025)\end{array}$ & $\begin{array}{l}0.048 \\
(0.031)\end{array}$ & $\begin{array}{l}0.090^{*} \\
(0.048)\end{array}$ & $\begin{array}{l}-0.033 \\
(0.042)\end{array}$ \\
\hline Units $=060$ When First $=020$ & $\begin{array}{l}0.117 \\
(0.078)\end{array}$ & $\begin{array}{l}0.146^{* *} \\
(0.077)\end{array}$ & $\begin{array}{l}0.171^{* *} \\
(0.077)\end{array}$ & $\begin{array}{l}0.122 \\
(0.079)\end{array}$ & $\begin{array}{l}0.193^{* *} \\
(0.074)\end{array}$ \\
\hline Units $=020$ When First $=100$ & $\begin{array}{l}0.133^{* * *} \\
(0.046)\end{array}$ & $\begin{array}{l}0.109^{* * * *} \\
(0.033)\end{array}$ & $\begin{array}{l}0.109 * * \\
(0.047)\end{array}$ & $\begin{array}{l}0.111^{*} \\
(0.056)\end{array}$ & $\begin{array}{l}0.051 \\
(0.084)\end{array}$ \\
\hline Units $=020$ When First $=020$ & $\begin{array}{l}0.082 \\
(0.079)\end{array}$ & $\begin{array}{l}0.170^{* * *} \\
(0.040)\end{array}$ & $\begin{array}{l}0.196^{* * *} \\
(0.063)\end{array}$ & $\begin{array}{l}0.146^{* *} \\
(0.071)\end{array}$ & $\begin{array}{l}0.159^{* *} \\
(0.071)\end{array}$ \\
\hline Round (by resource level) & $\begin{array}{l}0.0106^{* *} \\
(0.00435)\end{array}$ & $\begin{array}{c}0.00610 \\
(0.00499)\end{array}$ & $\begin{array}{l}0.0134^{* *} \\
(0.00641)\end{array}$ & $\begin{array}{l}0.00537 \\
(0.00877)\end{array}$ & $\begin{array}{l}-0.00988 \\
(0.0118)\end{array}$ \\
\hline Fraction Taken Upstream & - & $\begin{array}{c}0.221^{* * *} \\
(0.0742)\end{array}$ & $\begin{array}{l}0.163^{*} \\
(0.0972)\end{array}$ & $\begin{array}{l}0.215^{* *} \\
(0.101)\end{array}$ & $\begin{array}{l}0.827^{* * *} \\
(0.136)\end{array}$ \\
\hline Player C (relative to B) & - & $\begin{array}{c}0.0611 \\
(0.0467)\end{array}$ & - & - & - \\
\hline Player D (relative to B) & - & $\begin{array}{c}0.0774 \\
(0.0555)\end{array}$ & - & - & - \\
\hline Usoigua $(1 / 0)$ & $\begin{array}{l}-0.181^{* *} \\
(0.0748)\end{array}$ & $\begin{array}{c}0.0167 \\
(0.0632)\end{array}$ & $\begin{array}{l}0.0714 \\
(0.0489)\end{array}$ & $\begin{array}{l}-0.0697 \\
(0.0875)\end{array}$ & - \\
\hline Owner $(1 / 0)$ & $\begin{array}{l}-0.127 \\
(0.0809)\end{array}$ & $\begin{array}{c}0.0195 \\
(0.0454)\end{array}$ & $\begin{array}{l}0.0689 \\
(0.0653)\end{array}$ & $\begin{array}{l}0.0504 \\
(0.0841)\end{array}$ & $\begin{array}{l}-0.101 \\
(0.102)\end{array}$ \\
\hline Male $(1 / 0)$ & $\begin{array}{l}-0.189^{*} \\
(0.0975)\end{array}$ & $\begin{array}{c}-0.199^{* * *} \\
(0.0489)\end{array}$ & $\begin{array}{l}-0.236^{* * *} \\
(0.0644)\end{array}$ & $\begin{array}{l}-0.0889 \\
(0.108)\end{array}$ & $\begin{array}{l}-0.152^{* *} \\
(0.0671)\end{array}$ \\
\hline Education (years) & $\begin{array}{l}0.00261 \\
(0.00920)\end{array}$ & $\begin{array}{r}0.00767^{*} \\
(0.00415)\end{array}$ & $\begin{array}{l}-0.00153 \\
(0.00708)\end{array}$ & $\begin{array}{l}0.0218^{* * *} \\
(0.00609)\end{array}$ & $\begin{array}{l}0.00796 \\
(0.00740)\end{array}$ \\
\hline \# you know in session & $\begin{array}{l}0.00937 \\
(0.00700)\end{array}$ & $\begin{array}{c}-0.00841^{* *} \\
(0.00401)\end{array}$ & $\begin{array}{l}-0.0142^{* * *} \\
(0.00478)\end{array}$ & $\begin{array}{l}-0.0108 \\
(0.00662)\end{array}$ & $\begin{array}{l}0.000681 \\
(0.00732)\end{array}$ \\
\hline \# people in the session & $\begin{array}{l}-0.0167^{*} \\
(0.00473)\end{array}$ & $\begin{array}{r}-0.00656^{*} \\
(0.00338)\end{array}$ & $\begin{array}{l}-0.00430 \\
(0.00451)\end{array}$ & $\begin{array}{l}-0.00809 \\
(0.00674)\end{array}$ & $\begin{array}{l}-0.00771 \\
(0.00621)\end{array}$ \\
\hline constant (100 When First -100 ) [coefficient reflects other effects] & $\begin{array}{l}0.901^{* * *} \\
(0.173)\end{array}$ & $\begin{array}{c}0.648^{* * * *} \\
(0.092)\end{array}$ & $\begin{array}{l}0.704^{* * *} \\
(0.125)\end{array}$ & $\begin{array}{l}0.574^{* * *} \\
(0.193)\end{array}$ & $\begin{array}{l}0.215 \\
(0.182)\end{array}$ \\
\hline Observations & 767 & 1371 & 610 & 453 & 308 \\
\hline R-Squared & 0.226 & 0.218 & 0.273 & 0.240 & 0.323 \\
\hline
\end{tabular}

again separating Players A from Players B, C and D since the latter three always follow prior extractions. These results support those in Table 3. For instance, the columns for 60 units provide direct tests of the results stated above, i.e., for Players B, C and D starting with higher scarcity raises the shares extracted (also suggested by the coefficient for Players A but, as noted, for that position we are limited by data).

Most important in terms of considering alternative stories are the columns for 20 and 100 units, and in particular the result for round number (here coded from 1 to 12 to focus on the scarcities' timings). The reason is that - unlike for 60 units which by design always occur in rounds 5 to 8 - rounds with 20 or with 100 units are either the earliest or the latest rounds. Thus, for 20 and 100 units, that feature of the design of our treatments might appear to confound learning with any impacts of sequences for scarcity. However, Table 4 shows that there is no general learning process occurring across round here. Consider, for instance, that round's "impact" is positive for 100 units, for Players A or Players B, C and D. However, if that were a general learning process across time, it should also apply to rounds which feature 20 units. We see no such effect and for Players B, C and D we have enough data to confirm the coefficients differ.

\section{Discussion}

We employed framed field experiments, in rural Colombia, with farmers who have experience with the variability of water for irrigation. We tested for 'path dependence', or durable impacts of prior scarcities on current extraction. After reviewing theory about scarcity's impacts - including contrasting predictions for impacts of past resource scarcities - we described our design to test for the impacts of prior scarcity, using the randomization and experimental control that experiments provide to do cleaner comparisons.

Our results are not consistent with leading models of responses to scarcity focused on one's own benefits, which suggest that higher past scarcities will lower own marginal benefits and, thus, extraction. We found that when facing high resources currently, people are less other-regarding after high scarcity. That is consistent with models in which high past scarcity - because it leads one to leave little for others, which could generate 'cognitive dissonance' - instead lowers the weights one places on others' welfare. Such shifts, endogenous to one's past treatment of others, might help one to feel better about the past but also might lead to less other-regarding behavior in the future when contemplating collective action.

We were testing a new mechanism and in particular the effects of sequence or timing. Thus, we attempted neither to contradict nor to confirm others' net impacts of scarcity. Yet our result for durable selfishness, resulting from high early scarcity, perhaps could be seen as more consistent with findings by Blanco et al. (2015), or D'Exelle et al. (2009), who find that higher scarcity increases extraction on average (although we recall Ostrom's non-monotonic prediction, based upon own benefits, of some self-limitation as some scarcity arises, but then less for high scarcity). For our focus and result, the test of prior (within-subject) scarcity is critical. Between-group comparisons of groups that had not yet experienced different levels of prior resource scarcity may look very different.

Such tradeoffs could be explored and extended in many ways. Within such exploration of actors' extraction behaviors alone, we could experimentally shift the value functions for those downstream (for instance adding thresholds in production or consumption values experienced from downstream water), as well as upstream actors' exposure to information about them, to see if it affects endogenous weights. More generally, communications certainly could be permitted along the lines of many prior analyses - as perhaps having interacted with those downstream makes it less likely one lowers weights upon them.

Adding policy relevant interactions among participants could include allowing them the ability to endogenously form institutions. Going beyond communication, allowing the participants to create 
Table 4

Examining extraction behavior by resource level. (OLS, clustered by player, omitting players E, standard errors in parentheses).

\begin{tabular}{|c|c|c|c|c|c|c|}
\hline & Players A & Players A & Players A & Players B,C,D & Players B,C,D & Players B,C,D \\
\hline LHS $=\%$ extracted & Units $=100$ & Units $=060$ & Units $=020$ & Units $=100$ & Units $=060$ & Units $=020$ \\
\hline First $=020$ Units & - & $\begin{array}{l}0.0616 \\
(0.0734)\end{array}$ & - & - & $\begin{array}{c}0.0846^{*} \\
(0.0499)\end{array}$ & - \\
\hline Round \# (1-12) & $\begin{array}{l}0.0180^{*} \\
(0.00938)\end{array}$ & $\begin{array}{l}0.0116^{*} \\
(0.00663)\end{array}$ & $\begin{array}{l}0.00746 \\
(0.00816)\end{array}$ & $\begin{array}{l}0.0226^{* * *} \\
(0.00581)\end{array}$ & $\begin{array}{r}-0.000600 \\
(0.00807)\end{array}$ & $\begin{array}{l}-0.00506 \\
(0.00499)\end{array}$ \\
\hline \% Already taken & - & - & - & $\begin{array}{l}0.162 * \\
(0.0859)\end{array}$ & $\begin{array}{c}0.249^{* *} \\
(0.102)\end{array}$ & $\begin{array}{l}0.259^{* * *} \\
(0.0873)\end{array}$ \\
\hline Player C (vs. B) & - & - & - & $\begin{array}{l}0.0433 \\
(0.0554)\end{array}$ & $\begin{array}{c}0.0811 \\
(0.0570)\end{array}$ & $\begin{array}{l}0.0579 \\
(0.0507)\end{array}$ \\
\hline Player D (vs. B) & - & - & - & $\begin{array}{l}0.120^{*} \\
(0.0642)\end{array}$ & $\begin{array}{c}0.0486 \\
(0.0726)\end{array}$ & $\begin{array}{l}0.0633 \\
(0.0693)\end{array}$ \\
\hline Usoigua $(1 / 0)$ & $\begin{array}{l}-0.135 \\
(0.0948)\end{array}$ & $\begin{array}{l}-0.194^{* *} \\
(0.0766)\end{array}$ & $\begin{array}{l}-0.220^{* *} \\
(0.0839)\end{array}$ & $\begin{array}{l}0.0390 \\
(0.0577)\end{array}$ & $\begin{array}{c}-0.0349 \\
(0.127)\end{array}$ & $\begin{array}{l}0.0489 \\
(0.0627)\end{array}$ \\
\hline Male $(1 / 0)$ & $\begin{array}{l}-0.130 \\
(0.122)\end{array}$ & $\begin{array}{l}-0.248^{* *} \\
(0.105)\end{array}$ & $\begin{array}{l}-0.184^{* *} \\
(0.0909)\end{array}$ & $\begin{array}{l}-0.256^{* * *} \\
(0.0534)\end{array}$ & $\begin{array}{c}-0.189^{* * *} \\
(0.0617)\end{array}$ & $\begin{array}{l}-0.157^{* * *} \\
(0.0578)\end{array}$ \\
\hline Education & $\begin{array}{l}0.00321 \\
(0.0105)\end{array}$ & $\begin{array}{l}0.00674 \\
(0.0101)\end{array}$ & $\begin{array}{l}-0.00178 \\
(0.00850)\end{array}$ & $\begin{array}{l}0.00503 \\
(0.00504)\end{array}$ & $\begin{array}{c}0.00855 \\
(0.00554)\end{array}$ & $\begin{array}{l}0.00907^{* *} \\
(0.00441)\end{array}$ \\
\hline Owner/Not & $\begin{array}{l}-0.118 \\
(0.100)\end{array}$ & $\begin{array}{l}-0.158^{*} \\
(0.0934)\end{array}$ & $\begin{array}{l}-0.103 \\
(0.0769)\end{array}$ & $\begin{array}{l}0.0277 \\
(0.0513)\end{array}$ & $\begin{array}{c}0.00356 \\
(0.0600)\end{array}$ & $\begin{array}{l}0.0380 \\
(0.0499)\end{array}$ \\
\hline \# people know & $\begin{array}{l}0.00684 \\
(0.00882)\end{array}$ & $\begin{array}{l}0.00925 \\
(0.00783)\end{array}$ & $\begin{array}{l}0.0120^{*} \\
(0.00691)\end{array}$ & $\begin{array}{l}-0.00471 \\
(0.00437)\end{array}$ & $\begin{array}{r}-0.00791 \\
(0.00495)\end{array}$ & $\begin{array}{l}-0.0126^{* * *} \\
(0.00402)\end{array}$ \\
\hline \# in session & $\begin{array}{l}-0.0194^{* * *} \\
(0.00558)\end{array}$ & $\begin{array}{l}-0.0143^{* * *} \\
(0.00532)\end{array}$ & $\begin{array}{l}-0.0160^{* * *} \\
(0.00485)\end{array}$ & $\begin{array}{l}-0.0117^{* * *} \\
(0.00402)\end{array}$ & $\begin{array}{r}-0.00517 \\
(0.00417)\end{array}$ & $\begin{array}{c}-0.00214 \\
(0.00367)\end{array}$ \\
\hline constant & $\begin{array}{l}0.879 * * * \\
(0.204)\end{array}$ & $\begin{array}{l}0.894^{* * *} \\
(0.196)\end{array}$ & $\begin{array}{l}0.981^{* * *} \\
(0.178)\end{array}$ & $\begin{array}{l}0.775^{* * *} \\
(0.102)\end{array}$ & $\begin{array}{l}0.668^{* * * *} \\
(0.135)\end{array}$ & $\begin{array}{l}0.708^{* * *} \\
(0.107)\end{array}$ \\
\hline \#obs & 255 & 256 & 256 & 472 & 472 & 427 \\
\hline$R^{2}$ & 0.22 & 0.24 & 0.24 & 0.25 & 0.20 & 0.22 \\
\hline
\end{tabular}

rules - e.g., rotating the order of extraction - could permit further examination of endogenous shifts in one's weights upon others as a consequence of exogenous shocks to scarcity (to which rules could react too). From our results, we infer that cooperation for water-resources management could be less common (or its converse, increases in natural resource conflicts, ${ }^{16}$ could be more common) after a period of drought (e.g., linked to climate change) as high scarcity from external shocks seems to durably lower generosity. That should affect inferences about willingness to invest in new institutions given distributions of types. However, it would be of interest to go beyond such conjectures to a direct examination of such impacts.

\section{Acknowledgments}

We greatly appreciate the funding for this work from both CRED, at Columbia University, and CGC, at Duke University. For their helpful comments, we are grateful to Amar Hamoudi, Erika Weinthal and the participants at the presentations at CRED as well as the "Water and Light" conference of U. de Los Andes and U. of St. Gallen. We thank Héctor Plazas and Humberto Pérez for their extensive help with our field logistics as well as the recruitment of participants. We also thank Lina Moros for her assistance in implementing the experiments and both Laura Alayón and Abbie Turiansky for their contributions to our previous field work to learn about the setting. Last but certainly not the least, we thank for their extensive helpful comments the issue editors as well as three anonymous referees.

\section{Appendix A}

\section{A.1. Instructions}

We would like to thank you for accepting our invitation to these research exercises. These exercises are part of a scientific research project conducted by researchers from both National and international universities. The funds to cover these expenses have been donated by a

\footnotetext{
16 See, e.g., Homer-Dixon (1991, 1994, 1999); Libiszewski, 1992; Schnaiberg, 1994.
}

scientific body. Right now we count on XXX researchers supporting the implementation of this exercise.

Before starting we will give you $\$ 7000$ pesos to cover the costs of transportation, this money is yours, please keep it.

Now we are going to start reading the instructions and explaining todays activity.

Our objective is to understand how people make decisions. We will learn from what you decide. Please note that all of the decisions you make during these exercises, and any other information you communicate to us, will remain confidential. The only people who will see that information are the project researchers and we will not divulge your individual information to anybody.

In this exercise you could earn money. How much depends on the activity, your decisions and also the decisions of others. We do not know yet how much you will earn but it will be between $\$ 6000$ and $\$ 50.000$ approximately. The total money you earn will be approximated to the nearest $\$ 1000$ pesos. For example, if you earn $\$ 18.500$ pesos this amount will be approximated to $\$ 18.000$, but if you earn more than $\$ 18.500$, for example $\$ 18.800$ it will be approximated to $\$ 19.000$. Is this clear?

We use money in these exercises to make them more like real situations in which your decisions could earn you or cost you money. Any money that you may earn in these exercises is yours to keep and nobody will know what you've earned except the researchers. Besides participating in this exercise and having the chance of earn money, you will participate in a workshop in the coming days in order to jointly discuss the exercise. We will announce the day of the workshop in the coming days.

These exercises may be different from other exercises in which members of your community might have participated in the past. Therefore, any comment that you might have heard about the exercises may well not be relevant to the exercises in which you will participate today.

\section{A.1.1. Today's exercise will last 3 hours}

We want to emphasize that your participation is voluntary. You are free to leave at any time. However, if you retire from the exercise other participant might have to leave too because we need groups of 5 people, 
additionally to get paid you will need to stay until the end of the exercises. Today's exercises may take two to three hours. If you think you will not able to stay that long, please let us know now.

Again, at any point you can choose to leave. These exercises involve no risk to you. They are likely to provide benefits, specifically the earnings you can keep. Are you willing to participate? If so please sign the form you receive when you enter the room. (MONITOR READ THE FORM AND PICKS UP THE FORM ONCE IS SIGNED)

Let's start. So please do not talk with other participants, you might prevent others from understanding the instructions or it might spoil the exercise and we might have to cancel the activity. Please turn-off your cell phones to avoid interrupting the activity. Last, we would like to know if anyone has difficulties for reading or writing, in this way a monitor could help you.

(The monitor waits until someone let them know of their difficulties and be aware when reading the instructions)

If you have any further questions please raise your hand and your doubts will be solved individually.

This exercise it is intended to recreate a situation in which each person must make decisions about how much water to extract from the irrigation canal to irrigate its plots within an irrigation district. You have been selected to participate in five persons group among persons who have been subscribed to participate. Today there are playing $\mathrm{X}$ groups at the same time.

You will play for 12 rounds equivalent, for example, to 12 years. Each round resemble the moment of the year in which you need water to plant the same crops. All participants within your group have the same size and quality of land, they need water to plant the same crop you are planting.

Each round consists of one decision. Each player need to decide how much water to take from the water units available in the irrigation canal. Think as each unit of water you extract and use in the crop will have economic benefits. Each unit you collect during the game is equivalent to $\$ 100$ pesos. For example if you get 100 units during 12 rounds of the game you will receive $\$ 10.000$ pesos.

At the beginning of each round you will have 5 units of water obtained from the rain that produces you $\$ 500$ pesos. Remember that a unit of water equals to $\$ 100$ pesos. Therefore, the money you earn during the exercise is dependent on the water you take from the irrigation canal plus the 5 units of water you receive in each round. At the end of the game we will add up your earnings for each round.

At the beginning of the exercise each one of you will receive, FOR ALL THE ROUNDS, randomly a card marked with the following characters: A, $\mathrm{B}, \mathrm{C}, \mathrm{D}$ and $\mathrm{E}$. The letter written in the card is how the player will be identified during the round. The player identified with the letter " $\mathrm{A}$ " will be the first to decide how much water she/he takes to irrigate her/his plot. It means that characters on the cards define the order in which the properties of each player are situated through the irrigation canal [the monitor shows a draw in the poster that represents the situation]. On the poster we can see the irrigation canal, the direction of the water flow goes from top to bottom. How you can see, the property of participant " $\mathrm{A}$ " is first, then follows B, next C, D and finally E.

Is there any question? Please raise your hand

Each of you will know your position within the irrigation district but won't know the position assigned to other players in your group. In fact you won't know who is in your group. Please don't show the letter that has been assigned to you. It is confidential.

At the beginning of each round and before " $A$ " takes the first decision the monitor will inform to all players the units of water available in the irrigation canal.

A.1.2. The amount of water available in the irrigation canal depends on the climate conditions and could vary in each round

After being informed about the quantity of water units in the canal, the player who has the card with the letter " $A$ " decides how much water to take and writes down his/her private decision on the DECISION SHEET.

If you are not "A", you should also write on the decision sheet the amount you think $\mathrm{A}$ is going to extract. This is to protect A's identity. Therefore, monitors pick up the decision sheet from everybody even though only A has made a decision regarding how much water to take from the irrigation canal.

Once everyone has written down their decision, monitors will pickup the decision sheet of all participants. The Monitor will subtract the water extracted by "A" from the available water and write the remaining amount of water on the DECISION SHEET of each player.

Then, the player who has the card with the letter B decides how much water to take and writes down his/her decision on the DECISION SHEET (MONITOR SHOWS A POSTER WITH THE DECISION SHEET). If you are not $B$, you should also write in the decision sheet the amount you think B is going to extract. This is to protect B's identity. Therefore, monitors pick up the decision sheet from everybody even though only B has made a decision regarding how much water to take from the irrigation canal.

A.1.2.1. Monitor Explain Decision Sheet with A Poster. This process continues until player $\mathrm{E}$ has made a decision.

Note that each player might extract whatever he/she wants up to the units of water available. However, if a player takes all the units available the round is over and we will start a new round.

Let's see how decision sheet must be filling in. The monitor fills in gray columns, and white columns are filled in by each participant.

For example, the first column are the available units of water, the monitor announces that there are 50 units of water available in this round. " $A$ " extract 5 , so there will be 45 units available. After "A" extracts, monitor writes down on the third column from each player decision sheet. In the fourth column "A" writes down what he thinks $B$ is willing to extract. In this case 10 .

In this moment $\mathrm{B}$ writes down on the decision sheet the amount of water that it is willing to extract. If you are not B you must write on the decision sheet the quantity that you think B will extract. Remember you don't know who is B, you just know the one that you have been assigned, Once everyone have written their decisions, the monitors will pick up the decision sheets from all players.

A.1.2.2. Monitor Explains Decision Sheet for B. In the first column as I said before, the monitor announces that there are 50 units of water available for this round. The second column the player B writes down what they think A will extract, for example 10 . The third column is for the monitor to write the available units after A takes the decision. Let's remember that though B thought A was going to extract 10, A extracted 5, according to $A$ decision sheet.

A.1.2.3. Monitor Shows the First Poster. Monitor subtracts $50-5$ and writes down the available unit after A takes the decision in the third column.

On the fourth column each "B" player writes what he decides to extract. B decides to extract 8 and write it down on the decision sheet. If you are not B you must write too on the decision sheet what you think $\mathrm{B}$ is going to extract. Then, there will be 37 units available for $\mathrm{C}$ to make a decision. Then, the monitor writes what is left after "B" extracts on the fifth column.

This process continues until $\mathrm{E}$ takes the final decision. At the end of this decision a new round will begin.

Are there any questions?

Keep in mind that each participant extracts the number of units they want from the available units of water. Though, if a player extracts all available units in its turn, the round is over and a new round will begin.

Now, an example: The monitor writes on the decision sheet that there are available 50 water units in this round. With this information, "A" extract 5 , so there are now 45 units left and available for "B". $50-5=45$ 
B decides to extract 8 units. Then, there will be left 37 units available for $\mathrm{C}$. So for $\mathrm{C}$ to make the decision there are left $45-8=37$

$C$ extracts 10 . There will be left 27 units for $D$ to make the decision. $37-10=27$

D extracts 12. There are left 15 units for $\mathrm{E}$ to make the decision. Then, $27-12=15$

E decides to extract 15 and the round is over.

In this case, the total units of water and the income of each player will be the following:

A.1.2.4. Remember that at the beginning of each round you receive 5 units of water obtain from the Rain. Remember 1 unit of water equals $\$ 100$ pesos.

A: 5 units of rain water +5 extracted units $=10$ units; $10 * \$ 100=$ 1.000 pesos

B: 5 units of rain water +8 extracted units $=13$ units; $13 * \$ 100=$ 1.300 pesos

C: 5 units of rain water +10 extracted units $=15$ units; $15^{*} \$ 100=$ 1.500 pesos

D: 5 units of rain water +12 extracted units $=17$ units; $17 * \$ 100=$ 1.700 pesos

E: 5 units of rain water +15 extracted units $=20$ units; $20 * \$ 100=$ 2.000 pesos

It is very important to remember that the decisions are individual, it means, the numbers you write down on the game sheets are private and you must not show them to the others participants.

Are there any questions about this? Please rise your hand [MONITOR: pause to resolve questions in private.]

The pesos you earn in each round depend on your own decisions and will be added up at the end of the exercise.

You will keep a record of your decisions and earnings in the player calculation sheet.

A.1.2.5. Monitor Shows a Poster with the Calculation Sheet and Uses One Example Above to Explain How to Fill in the Numbers. Each player must fill in the calculation sheet. For this example we are going to see the calculation sheet from B based on the last example. It works the same way for all players.

The available units of water are in the first column, Player B writes 50 on the calculation sheet.

The available units before my turn are written in the second column, in this case 45 units.

On the third column you must write the level of extraction, in this case for B. The number written on the calculation sheet is the same number on the decision sheet, for this specific example: 8 units.

The fourth column represents the total earnings. The total earnings are the rainwater and the extracted units. For this example there are $\$ 500$ pesos (first rainwater units times $\$ 100$ pesos) plus $\$ 800$ pesos (from the extracted units ( $8 * \$ 100$ pesos)). Therefore the total earnings on this round are $\$ 500$ pesos $+\$ 800$ pesos $=\$ 1.300$ pesos.

Is there any question about this? Please raise your hand.

To start the first round of the game we will organize the seats and desks so you are not close to other participants and we can guarantee your decisions are private.

Finally, to get ready to play the game, please let us know if you have difficulties reading or writing numbers and one of the monitors will seat next to you to assist you with these.

Also keep in mind that from now on no conversation or statements should be made by you during the game unless you are allowed to.

First we will ask you a couple of questions to make sure you understand the game: Remember you are not allowed to talk with other players during the exercise. As soon as you finish raise your hand and the monitor will check your answers.

\section{A.2. Quiz}

Please fill the blank with the correct answer:

If there are 40 units of water and extract 3 , there will be units available for $\mathrm{B}$ to make a decision. Then 6. Then, there will be units available for decides to extract C extracts 8 . Then, there will be decision.___ extracts 10. There are ___ units left for $\mathrm{E}$ to make decision.__ extracts 10. There are ___ units left for E to make units available for $\mathrm{D}$ to make a a decision. E decides to extract 13. (MONITOR WRITES EACH DECISION IN THE POSTER) In that case earnings for that round will be:
A: $7+3$ units: pesos
B: $7+6$ units: pesos
C: $7+8$ units: pesos
D: $7+10$ units: pesos
E: $7+13$ units: pesos

Now, you will randomly select from this BAG the card marked with the following characters: A, B, C, D and E and your group number. Remember this card is confidential. Please put it downwards under the table.

We are ready to start.

At this moment you are going to receive the decision and calculation sheet, please write down on the calculation sheet the letter and number of the group. (MONITOR: check with each participant that IT IS clear the card and group number, including the poster they need to look at).

We will have a round of practice that will NOT count for the real earnings, just for practicing of the game.

\section{References}

Agrawal, Arun, 2001. Common property institutions and sustainable governance of resources. World Dev. 29 (10), 1649-1672.

Andreoni, James, 2007. Giving gifts to groups: how altruism depends on the number of recipients. J. Public Econ. 91 (9), 1731-1749.

Araral, Eduardo, 2009. What explains collective action in the commons? Theory and evidence from the Philippines. World Dev. 37 (3), 687-697.

Aronson, Elliot, 1976. The Social Animal. 2nd ed. W.H. Freeman, San Francisco.

Benjamin, Paul, Lam, Wai Fung, Ostrom, Elinor, Shivakoti, Ganesh, 1994. Institutions, Incentives, and Irrigation in Nepal. Decentralization: Finance \& Management Project Report. Associates in Rural Development, Burlington, VT.

Bernauer, Thomas, Böhmelt, Tobias, Koubi, Vally, 2012. Environmental changes and violent conflict. Environ. Res. Lett. 7, 1-8.

Blanco, Esther, Claudia Lopez, Maria, Villamayor, Sergio, 2015. Exogenous degradation in the commons: field experimental evidence. Ecol. Econ. 120, 430-439.

Bob, Urmilla, Bronkhorst, Salomé, 2010. Environmental conflicts: key issues and management implications. Afr. J. Confl. Resolut. 10 (2), 9-30.

Bogale, Ayalneh, Korf, Benedikt, 2007. To share or not to share? (non-)violence, scarcity and resource access in Somali Region, Ethiopia. J. Dev. Stud. 43 (4), 743-765.

Bolton, G., Katok, E., Zwick, R., 1998, August. Dictator game giving: Rules of fairness versus acts of kindness. Int. J. Game Theory 27 (2), 269-299.

Bowles, Samuel, 1998. Endogenous preferences: the cultural consequences of markets and other economic institutions. J. Econ. Lit. 36 (1), 75-111.

Brañas-Garza, Pablo, 2006. Poverty in dictator games: awakening solidarity. J. Econ. Behav. Organ. 60 (3), 306-320.

Camerer, Colin, Fehr, Ernst, 2006. When does 'economic man' dominate social behavior? Science 311 (5757), 47-52.

Cardenas, Juan Camilo, Ostrom, Elinor, 2004. What do people bring into the game? Experiments in the field about cooperation in the commons. Agric. Syst. 82 (3), 307-326.

Cardenas, Juan Camilo, Rodriguez, Luz Ángela, Johnson, Nancy, 2011. Collective action and water management: field experiments in Colombia and Kenya. Environ. Dev. Econ. 16 (3), 275-303.

Cardenas, Juan Camilo, Janssen, Marco, Bousquet, Francois, 2013. Dynamics of Rules and Resources: Three New Field Experiments on Water, Forests and Fisheries. In: List, John, Price, Michael (Eds.), Handbook on Experimental Economics and the Environment. Edward Elgar, pp. 319-345.

Carpenter, Jeffrey, Verhoogenb, Eric, Burks, Stephen, 2005. The effect of stakes in distribution experiments. Econ. Lett. 86, 393-398.

Carter, Michael, Castillo, Marco, 2005. Coping with Disaster: Morals, Markets and Mutual Insurance. Using Economic Experiments to Study Recovery from Hurricane Mitch. In: Barrett, Christopher (Ed.), The Social Economics of Poverty: On Identities, Communities, Groups, and Networks. Routledge, London, pp. 268-287.

Charness, Gary, Rabin, Mathew, 2002. Understanding social preferences with simple tests. Q. J. Econ. 117 (3), 817-869.

D'Exelle, Ben, Lecoutere, Els, Van Campenhout, Bjorn, 2009. Water Distribution in Africa: The behavioral Relevance of Scarcity and Social Status. Working Paper. 
de Rooij, Eline, Green, Donald, Gerber, Alan, 2009. Field experiments on political behavior and collective action. Annu. Rev. Polit. Sci. 12, 389-395.

Dinar, A., Howitt, R.E., Murphy, J.J., Rassenti, S.J., Smith, D.V., 2000. The role of spot prices, water storage and forward contracts in a "smart" water market mechanism. Proceedings of the 22nd Annual Research Conference. Association for Public Policy Analysis and Management, Seattle.

Dittmer, John, 1977. Black Georgia in the Progressive Era, 1900-1920. University of Illinois Press.

Engel, Christoph, 2011. Dictator games: a meta study. Exp. Econ. 14 (4), 583-610.

Feeny, David, Berkes, Firket, McCay, Bonnie, Acheson, James, 1990. The tragedy of the commons: twenty-two years later. Hum. Ecol. 18 (1), 1-19.

Feeny, David, Hanna, Susan, McEvoy, Arthur, 1996. Questioning the assumptions of the "tragedy of the commons" model of fisheries. Land Econ. 72 (2), 187-205.

Festinger, Leon, 1957. A Theory of Cognitive Dissonance. Stanford University Press, Stanford, CA.

Fischer, Maria-Elisabeth, Irlenbusch, Bernd, Sadrieh, Abdolkarim, 2004. An intergenerational common pool resource experiment. J. Environ. Econ. Manag. 48, 811-836.

Forsythe, Rrobert, Horowitz, Joel, Savin, Eugene, Sefton, Martin, 1994. Fairness in simple bargaining experiments. Games Econ. Behav. 6, 347-369.

Glaser, S.M., Hendrix, C., Faufman, L., Mahoney, C., 2013. Conflict and Fisheries in the Lake Victoria Basin: A Coupled Natural and Human Systems Approach. APSA 2013 Annual Meeting Paper; American Political Science Association 2013 Annual Meeting. Available at SSRN: http://ssrn.com/abstract $=2300188$.

Gleditsch, Kristian, Metternich, Nils, Ruggeri, Andrea, 2013. Data and progress in peace and conflict research. J. Peace Res. 3, 1-14 (October).

Green, Donald, Gerber, Alan, 2003. The underprovision of experiments in political science Ann. Am. Acad. Pol. Soc. Sci. 589, 94-112.

Green, Donald, Thorley, Dane, 2014. Field experimentation and the study of Law and Policy. Annu. Rev. Law Soc. Sci. 10, 53-72.

Greif, Avner, 2014. Do institutions evolve? J. Bioecon. 16 (1), 53-60.

Grossman, H.I., Mendoza, J., 2003. Scarcity and appropriative competition. Eur. J. Polit Econ. 19 (4), 747-758.

Hagmann, Tobias, 2005. Confronting the concept of environmentally induced conflict. Peace Confl. Dev. 6, 1-22.

Harrison, G.W., List, J., 2004. Field experiments. J. Econ. Lit. 52, 1009-1055.

Henrich, Joseph Patrick, Boyd, Robert, Bowles, Samuel, Camerer, Colin, Fehr, Ernst, Gintis, Herbert, McElreath, Richard, 2001. In search of homo economicus: behaviora experiments in 15 small-scale societies. Am. Econ. Rev. 91 (73), 78 (11).

Holt, Charles A., Johnson, Cathleen A., Mallow, Courtney A., Sullivan, Sean P., 2012. Water externalities: tragedy of the common canal. South. Econ. J. 78 (4), 1142-1162.

Homer-Dixon, Thomas, 1991. On the threshold: environmental changes as causes of acute conflict. Int. Secur. 19, 5-40.

Homer-Dixon, Thomas, 1994. Environmental scarcities and violent conflict: evidence from cases. Int. Secur. 19 (1), 5-40.

Homer-Dixon, T., 1999. Environment, Scarcity, Violence. Princeton University Press, Princeton NJ.

Konow, James, 2000. Fair shares: accountability and cognitive dissonance in allocation decisions. Am. Econ. Rev. 90 (4), 1072-1091.

Lam, Wai Fung, 1998. Governing Irrigation Systems in Nepal: Institutions, Infrastructure, and Collective Action. ICS Press, Oakland, CA.

Lecoutere, Els, D'Exelle, Ben, Van Campenhout, Bjorn, 2010. Who Engages in Water Scarcity Conflicts? A Field Experiment with Irrigators in Semi-arid Africa. MICROCON Working Paper No.31.

Libiszewski, S., 1992. What is Environmental Conflict? Retrieved from Center For Security Studies website: http://www.css.ethz.ch

List, John, Cherry, Todd, 2008. Examining the role of fairness in high stakes allocation decision. J. Econ. Behav. Organ. 65 (1), 1-8.

Mani, Amandi, Mullainathan, Senhil, Shafir, Eldar, Zhao, Jiaying, 2013. Poverty impedes cognitive function. Science 341, 976-980.

Mayer, Frederick W., 2014. Narrative Politics: Stories and Collective Action. Oxford University Press, New York, NY (forthcoming).

Meierding, Emily, 2013. Climate change and conflict: avoiding small talk about the weather. Int. Stud. Rev. 15, 185-203.

Moreno-Sánchez, Rocio del Pilar, Maldonado, Jorge Higinio, 2010. Evaluating the role of co-management in improving governance of marine protected areas: an experimental approach in the Colombian Caribbean. Ecol. Econ. 69, 2557-2567.
Mullainathan, Sendhil, Shafir, Eldar, 2013. Scarcity. Why Having too Little Means so Much. Penguin, USA.

Murphy, J.J., Dinar, A., Howitt, R.E., Rassenti, S.J., Smith, V., 2000. The design of "smart" water market institutions using laboratoy experiments. Environ. Resour. Econ. 17, 375-395.

Ockenfels, Axel, Werner, Peter, 2012. 'Hiding behind a small cake' in a newspaper dictator game. J. Econ. Behav. Organ. 82, 82-85.

Osés-Eraso, Nuria, Viladrich-Grau, Montserrat, 2007. Appropriation and concern for resource scarcity in the commons: an experimental study. Ecol. Econ. 63 (2), 435-445.

Osés-Eraso, Nuria, Udina, Frederic, Viladrich-Grau, Montserrat, 2008. Environmental versus human-induced scarcity in the commons: do they trigger the same response? Environ. Resour. Econ. 40 (4), 529-550.

Ostrom, Elinor, 1990. Governing the Commons: The Evolution of Institutions for Collective Action. University Press, Cambridge.

Ostrom, Elinor, 1998. "A behavioral approach to the rational choice theory of collective action". presidential address American Political Science Association, 1997. Am. Polit. Sci. Rev. 92 (1), 1-22.

Ostrom, Elinor, 2009a. A general framework for analyzing the sustainability of socialecological systems. Science 325 (5939), 419-422.

Ostrom, Elinor, 2009b. Understanding Institutional Diversity. Princeton University Press.

Ostrom, Elinor, Gardner, Roy, 1993. Coping with asymmetries in the commons: selfgoverning irrigation systems can work. J. Econ. Perspect. 7 (4), 93-112.

Ostrom, Elinor, Lam, Wai Fung, Myungsuk, Lee, 1994a. The performance of self-governing irrigation systems in Nepal. Hum. Syst. Manag. 14 (3), 87-108.

Ostrom, Elinor, Gardner, Roy, Walker, James, 1994b. Rules, Games and Common-Pool Resources. University of Michigan Press, MI.

Pfaff, Alexander, Velez, Maria Alejandra, Taddei, Renzo, Broad, Kenneth, 2015a. Unequal information, unequal allocation: bargaining field experiments in NE Brazil. Environ. Sci. Pol. 26, 90-101.

Pfaff, Alexander, Velez, Maria Alejandra, Taddei, Renzo, Broad, Kenneth, 2015b. Contracts versus Trust in Resource Reallocation: Evolution of Efficiency and Equity with Repeated Interaction. University Mimeo, Duke.

Reuveny, Rafael, Maxwell, John, 2001. Conflict and renewable resources. J. Confl. Resolut. 45 (6), 719-742.

Rutte, Christel, Wilke, Hem A.M., 1987. Scarcity or abundance caused by people or the environment as determinants of behavior in the resource dilemma. J. Exp. Soc. Psychol. 23, 208-216.

Schnaiberg, Allan, 1994. The political economy of environmental problems and policies: consciousness, conflict and control capacity. Adv. Hum. Ecol. 3, 23-54.

Schwartz, Daniel, Deligiannis, Tom, Homer-Dixon, Thomas, 2000. The Environment and Violent Conflict: A Response to Gleditsch's Critique and Some Suggestions for Future Research. Environmental Change and Security Project Report vol. 6 (http://www.unipotsdam.de/u/sprinz/doc/ECSP\%20Report6-5.pdf).

Sekhon, Jasjeet S., Titiunik, Rocio, 2012. When natural experiments are neither natural nor experiments. Am. Polit. Sci. Rev. 106 (1), 35-57.

Shah, Anuj K., Mullainathan, Sendhil, Shafir, Eldar, 2012. Some consequences of having too little. Science 338, 682-685.

Shivakoti, Ganesh, Ostrom, Elinor, 2002. Improving Irrigation Governance and Management in Nepal. ICS Press, Oakland, CA.

Slotkin, Richard, 2000. Regeneration through Violence: The Mythology of the American Frontier 1600-1860. University of Oklahoma Press.

Stahl, Dale O., Haruvy, Ernan, 2006. Other-regarding preferences: Egalitarian warm glow, empathy, and group size. J. Econ. Behav. Organ. 61 (1), 20-41.

Theisen, Ole Magnus, Gleditsch, Nils P., Buhaug, Halvard, 2013. Is climate change a driver of armed conflict? Climate Change 117, 613-625.

Timura, Chistopher, 2001. 'Environmental conflict' and the social life of environmental security discourse. Anthropol. 0. 74 (3), 104-113.

Tversky, Amos, Kahneman, Daniel, 1986. Rational choice and the framing of decisions. J. Bus. 59 (4), S251-S278.

Velez, Maria Alejandra, Ramos, Pablo, Alayón, Laura, 2011. Instituciones Anidadas para prevenir y resolver conflictos socio-ambientales: manejo y distribución del agua en Campo Alegre (Huila, Colombia). Cuad. Desarrollo Rural 8 (67), 71-90.

Zimbardo, Philip G., 1969. The cognitive control of motivation. Scott, Foresman, Atlanta, GA. 